\title{
THE CYTOLOGICAL BASIS FOR HOMOTHALLISM AND HETEROTHALLISM IN THE AGARICACEAE ${ }^{1}$
}

JOHN E. SASS

\author{
(Received for publication May 8, 1929)
}

\section{Statement of Problem}

In most of the previous studies on sexuality in the Hymenomycetes, cytological work has been a minor feature. Furthermore, in practically all studies on sex in this group, the basidia of the fungi used were four-spored. The sex reactions of the four-spored species are explainable in terms of sex factors and the distribution of these factors is explicable on the basis of known nuclear events.

A number of species or forms among the agarics are known to have twospored basidia. In such cases there are theoretically possible a number of variations from the typical nuclear cycle found in four-spored forms. The problem then presented itself of determining, in these two-spored forms, which of the theoretical possibilities existed in fact; what cytological phenomena underlie homothallism and heterothallism in these fungi; and to what extent additional light could be thrown on the detailed nuclear phenomena in the agarics.

\section{Historical Sketch}

The discovery in 1918-1919 of heterothallism in the Hymenomycetes opened up a fertile field of investigation in the higher fungi, and during the following decade our knowledge of sex phenomena has been extended to include a considerable number of Hymenomycetes and a few Ascomycetes. The recent discovery of heterothallism in important pathogens, the rusts and smuts, has added a new and vital emphasis to the problem of sexuality in fungi. Gaumann's (7) excellent review of this subject is now available in English as well as German and the present writer will therefore limit the following review to the most pertinent items in the older literature and to the recent developments in the field. It seems desirable to subordinate chronological sequence to a convenient grouping of related phases of. the subject.

Mlle. Bensaude (2), who first announced the discovery of heterothallism in the Hymenomycetes, isolated two haploid (primary) mycelia of Coprinus fimetarius Fr. and showed that these mycelia conjugate, giving rise to a diploid (secondary) mycelium. The work of Mlle. Bensaude, especially her cytological studies, established clearly the existence of heterothallism. Her

${ }^{1}$ Papers from the Department of Botany of the University of Michigan, no. $3^{\text {I2. }}$ 
results suggested a case of bisexuality, but since only two mycelia were isolated the data were too meager to show the true situation in this species.

Miss Mounce (24) repeated Mlle. Bensaude's mating experiments, using Coprinus lagopus Fr. which she considered to be identical with Mlle. Bensaude's $C$. fimetarius. 'Miss Mounce isolated a large number of monosporous mycelia which she paired in all possible combinations, and found that C. lagopus is heterothallic, but that it is not bisexual. The data indicated that there are more than two sex groups. Mlle. Bensaude and Miss Mounce did not interpret their results on the basis of Mendelian sex factors; later workers, however, have made such interpretations.

Hanna (8) followed up the work of Mlle. Bensaude and Miss Mounce with a critical analysis of sexuality in Coprinus lagopus. Hanna was able to isolate the members of spore tetrads from individual basidia and mated the monosporous mycelia. He found that in some cases any monosporous mycelium from a tetrad crosses with only one other member of the same tetrad, indicating that this species is quadrisexual. According to Hanna, different fruit bodies may have unlike sex groups, resulting in complete fertility between monosporous mycelia of two such fruit bodies. Some basidia bear two spores of one sex group and two spores of an opposite group. The factorial interpretation applied by Hanna to sexuality in Coprinus lagopus is that two pairs of independently segregating Mendelian factors are involved. The fusion nucleus in the basidium bears the complete set of sex factors $(A a B b)$. If disjunction occurs in a basidium during the first division of meiosis, that basidium forms four spores which fall into two sex groups, bearing respectively the factors $(A B),(A b),(a b),(a B)$. Similar results have been obtained in genera other than Coprinus (Kniep; I6).

Shortly after the publication of Mlle. Bensaude's paper, Kniep (I5) reported that Schizophyllum commune Fr. is normally quadrisexual. Some monosporous mycelia fruited but all the spores from these haploid fruit bodies were of the same sex class, since no crossing occurred in any combination of matings. In subsequent investigations Kniep (16) was able to isolate spore tetrads from individual basidia of Aleurodiscus polygonius (Pers.) v. Haehn. and Litsch., and to show that in this species the four spores of a tetrad belong respectively to four different sex groups. In some tetrads, however, two spores were of one sex and two spores were of an opposite sex. In order to explain the type of heterothallism found in Schizophyllum commune and Aleurodiscus polygonius, Kniep proposed the interpretation, also used by Hanna, that in a quadrisexual form sex is determined by two pairs of allelomorphic sex factors, the pairs segregating independently of each other, and during the second division of meiosis. In the exceptional basidia bearing but two kinds of spores, the disjunction of sex factors may be assumed to have occurred at the first division. A number of other cases of quadrisexuality have been reported in Coprinus and in species of Collybia and Hypholoma. 
A clear-cut case of bisexuality was found in Coprinus rostrupianus Hansen by Miss Newton (25). In this species, primary mycelia of monosporous origin fall into two sex classes, and any member of one class crosses with any member of the other class. In this case it is assumed that the fusion nucleus in the basidium carried one pair of sex factors $(A a)$. During meiosis the members of the pair are disjoined, two of the tetracyte nuclei thus receive one kind of factor $(A)$ and the other two nuclei receive the opposite factor $(a)$. A spore thus receives one factor and gives rise to a mycelium in which the cells are uninucleate, and every nucleus carries the same factor. The conjugation of mycelial cells carrying unlike factors initiates the binucleate mycelium.

Exceptions to regular Mendelian behavior have been described in severa cases of heterothallism. It has been suggested that factor mutations occur with some frequency, especially in Coprinus.

Homothallism was first definitely demonstrated by Miss Mounce (23) in Coprinus sterquilinus Fr. and C. stercorarius Fr. Brunswik (3) has verified Miss Mounce's results on the above species and added further that $C$. narcoticus Fr. and $C$. ephemeroides Fr. are also homothallic. Vandendries (30) found that $C$. radians $F r$. is homothallic, but the appearance of the diploid condition is more or less delayed. Explanations of sex in homothallic species are largely speculative because normal homothallism offers little clue to the existence or behavior of sex factors. Exceptional behavior in. four-spored homothallic species is not established. Aberrant heterothallism in a two-spored homothallic form was reported by the writer (27) and this case as well as other cases will be treated more fully in the present paper.

Heterothallism has been definitely shown to occur in the smuts. The nuclear cycle conforms in general to the condition found in the Hymenomycetes, having a cyclic alternation of the haploid and the diploid condition. Among the latest developments may be mentioned the work of Stakman and Christensen on Ustilago zeae (Beck) Unger (29). In this smut there are two sex classes, and the formation of smut galls is believed to be preceded by hyphal conjugations comparable to those occurring in some species of $\mathrm{Co}$ prinus.

Dickinson (5) found a similar condition in Ustilago levis Jens. He was able to isolate tetrads of sporidia and showed that the respective mycelia of the four members of a tetrad differ from each other in several vegetative characters. Since these characters appear in the haplophase, they are evidence of the independent segregation of factors. These phenomena bring us closer to the actual manifestations of segregation than any previous genetic work on the diploid body.

The results of recent work on sex in the rust fungi promise to bring about a revision of our conception of sex in this group. It seems that the binucleate condition does not arise in all species through conjugation in the 
aecial hymenium, but it is possible that conjugation occurs farther back in the life history at some point comparable to hyphal conjugation in the Hymenomycetes.

\section{Materials and Methods}

The agarics used in this study were either collected in the field or came up in the laboratory on samples of unsterilized dung, soil, wood, and other substrata. Spore deposits were made in sterile petri dishes and these were stored at a temperature of $3-5^{\circ} \mathrm{C}$. In this way the spores of certain species remained viable for over a year. This length of time was more than sufficient because the fungi studied were collected repeatedly at the proper seasons during four years. It is obviously an advantage to have fruiting in pure culture the agarics that are being studied cytologically, since there can then be no doubt about the identity of minute button stages of a mushroom. There is often a strong element of uncertainty in identifying young stages collected in the field. Furthermore, the spores produced in pure culture are of known origin. It is well known to anyone who has studied the hymenia of mushrooms, that wild fruit bodies are constantly visited by insects and there is the possibility that spores from one fruit body are carried to another fruit body. On this account single-spore cultures were made of all the species studied. Since the primary object of the culturing was to have fresh material available for cytological study, very little time was devoted to the physiological factors involved, and the media used were mostly of undetermined composition, such as sterilized dung, dung extract agar, and malt extract agar. Fruiting was obtained only in Coprinus.

In the cytological work standard methods were used, for the most part. For the study of the hymenium, each fruit body was carefully cut up and pieces were killed in two or three different killing agents. The principal killing fluids used were Flemming's fluid of various dilutions, Bouin's picroformol, acetic-formalin-alcohol, Chamberlain's osmic formula, and Licent's fluid. The visual results of course vary with the fixation used and certain peculiarities merit special mention in connection with the data.

In order to obtain rapid penetration of the killing fluid it was necessary to pump out the air from between the gills. The pieces of a pileus were placed in a small cylinder of fine-meshed wire gauze and the cylinder was inverted in a thick-walled test tube and covered with the desired killing fluid. The test tube was attached to an aspirator and suction was applied and released repeatedly until the material sank. At $40^{\circ} \mathrm{C}$. this required scarcely a minute. The material was then transferred to a large volume of fresh killing fluid. One hour is ample for killing most forms in which the gills are freely exposed to the fluid. Closed button stages may require longer. Some of the finest figures were obtained in material which was in the killing fluid five minutes. Washing, dehydrating, and imbedding were carried out in the usual manner; the fragile texture of the object obviously 
requires that unusual caution be exercised in handling the material. Microtome sections were cut $2 \mu$ to $8 \mu$ in thickness, depending on the parts to be cut and the purpose for which they were to be used.

Several stains were used because it was found that one stain may be satisfactory for a certain phase of the nuclear cycle but may be nearly useless for another phase, for which another stain is very good. The principal stain combinations used were:

I. Aqueous safranin counterstained with aqueous crystal violet, or with crystal violet in clove oil.

2. Aqueous basic fuchsin (containing a trace of phenol), counterstained with Light Green S. F. or "Fast Green" in 95-percent alcohol.

3. Iron-alum haematoxylin, usually without a counterstain. A light stain of slightly alkaline Fast Green stains the walls of vegetative mycelium and fruit body cells very sharply.

4. For a rapid examination of material, the following progressive stain, based on unpublished work by Mr. W. K. Bowen of Ann Arbor, Mich., was found to be useful for making nuclear counts. To one volume of Mayer's haem-alum (oxidized with .002 percent $\mathrm{NaIO}_{3}$ ) add one volume of four-percent ammonium alum. Add two percent glacial acetic acid. This is a fair nuclear stain. It stains in fifteen minutes and requires no differentiation.

The nuclei in the mature spores of Coprinus ephemerus cannot be satisfactorily demonstrated by sectioning fruit bodies, because of the early and complete deliquescence of the fruit bodies. The following method was therefore used. Several expanded caps which were about to undergo autodigestion were put into a centrifuge tube and allowed to deliquesce. The mass was washed several times with distilled water, by centrifuging and decanting. Bouin's fluid was then poured over the spore mass and stirred. After twenty-four hours the material was washed, dehydrated, and imbedded in paraffin. In this way, sectioning was very productive because hundreds of spores were cut at each stroke. The sections were cut slightly thinner than the shorter diameter of the spore. If a spore happens to be cut parallel to its long axis and a thin slice is cut from the opposite sides of the spore, the interior can be stained and examined. The nucleolus stains well with iron haematoxylin and in a strongly destained preparation the clear-cut nucleoli can be counted with some certainty. In a heavily stained preparation the outline of the entire nucleus is evident.

A modification of Kniep's (12) agar film method was used in the cytological study of spore germination and of the mycelium. The writer (28) has described a modification of this method in a previous paper. Further improvements have since been made and the method used at present is as follows: Dissolve 3 grams of agar and I 5 grams of gelatin in one liter of distilled water. Filter by suction through quantitative filter paper. Sterilize at $100^{\circ} \mathrm{C}$. This medium should be semi-solid at ordinary temperatures and become fluid when slightly warmed. Drop two drops of this on a 
perfectly clean, sterile slide and stir the spores into the fluid. For the study of vegetative mycelium, inoculate the film with a piece of mycelium. Incubate in a sterile moist chamber, examining when necessary under sterile conditions. If only the early stages of germination are to be studied, no nutrient is required but if extensive growth of mycelium is desired, the film may be moistened after a day or two with a drop of sterile, well-filtered dung infusion. When the culture has reached the desired condition transfer the slide into a dry petri dish and allow the film to dry down. The extent of drying must be learned by experience. If the film remains too fluid, it washes off, while if it becomes too dry, the mycelium is damaged. Immerse the slide, film side up, in the following solution:

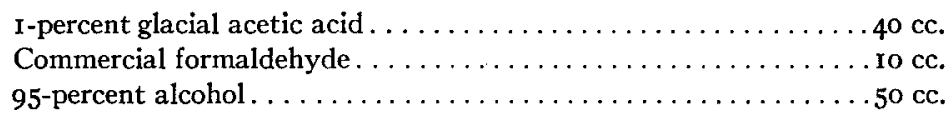

This solution hardens the film better than the formula previously suggested by the writer and the fixation is good. Other killing fluids may be used. The best nuclear detail was obtained with Flemming's weak solution. It was rather difficult to keep the film intact with solutions other than the one given above. After 12 hours in this solution, rinse the slide in 50-percent alcohol, wash in water, and stain in iron haematoxylin. The gelatin stains deeply, but it also destains readily. Since stain differentiation cannot be watched under the microscope with this subject, the destaining of the film affords a convenient guide to the progress of differentiation.

In order to show the degree of certainty with which single spores were isolated in this work, a few words should be devoted to the method used. The following is adapted to the isolation of large, colored spores: A spore suspension is made in water and is sprayed through a capillary pipette over the surface of agar in a small $(75-\mathrm{mm}$.) petri dish. With the proper degree of dilution, the spores are well separated from each other on the surface of the agar. After the spores have germinated, the bottom of the dish is marked off into nine sections and the dish is placed, inverted, on the mechanical superstage which will be described later. With a $25-\mathrm{mm}$. objective of long working distance, the dish is systematically examined. Any desired germinated spore may be further examined with a I6-mm. objective and if satisfactory, it is located with a dot of India ink.

A simple spore cutter, shown in text figure $I$, is made as follows. The end of a piece of $\mathrm{r}_{4}$ gauge nichrome wire is hammered out into spatulate form and the surfaces ground smooth. By means of the cork-and-needle method a clean hole about $1.5 \mathrm{~mm}$. in diameter is punched through the metal. The metal is somewhat crater shaped around the hole, with a rim on the convex side, as illustrated, When this convex surface is pressed down on the agar surface, with the desired spore in the hole, a clean-cut disc of agar bearing the spore is pushed up through the hole and is easily picked off. 
The entire operation may be performed under a $32-\mathrm{mm}$. objective and the spore kept in sight until it is, transferred to another petri dish.

A rapid and convenient method is used by the writer in this type of work for estimating the percentage of spore germination. A wire loop is dipped

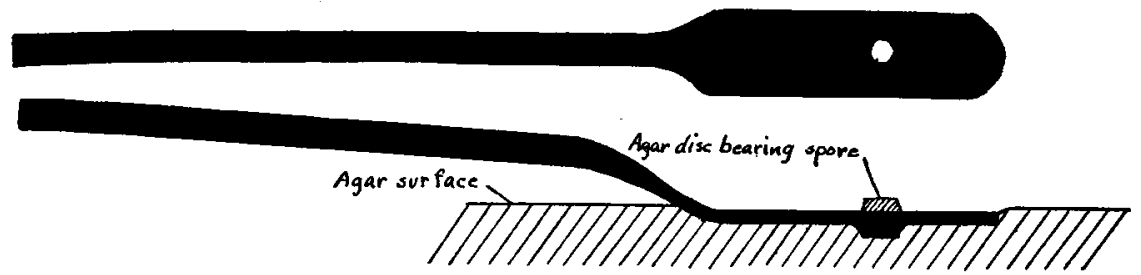

TExT FIG. I. Spore isolator, showing cutting action on agar.

into a spore mass and the edge of the loop is drawn gently in a straight line over the surface of agar in a petri dish. It the agar surface is broken, the refraction of light on the uneven streak interferes with visibility under the microscope, but if the streak is properly made, the spores are well separated and the entire width of streak lies within a low-power field of the microscope. After the necessary period of incubation, the dish is examined on a mechanical stage. By drawing the spore streak past a given line of the eyepiece micrometer, the germinated and ungerminated spores are readily counted. The writer has made a metal platform which fastens over the regular mechanical stage. A petri dish may be placed on the platform, either inverted or right side up with the cover removed, and the culture systematically examined with the aid of the mechanical movement. The newer microscopes having a mechanical stage with a perfectly smooth top (except for the removable clips) afford an even more convenient means of locating spores.

\section{Cultural and Cytological Data}

\section{Coprinus ephemerus Fr. forma bisporus, forma nov. ${ }^{2}$}

A two-spored form of Coprinus ephemerus Fr. is described by Pennington in Kauffman's "Agaricaceae of Michigan" (I9r8). I have isolated a twospored form and have had it in pure culture for four years. It has remained

${ }^{2}$ Pileus $1.5^{-2} \mathrm{~cm}$. high, $\mathrm{I}-1.5 \mathrm{~cm}$. broad, just before rapid expansion begins, attaining a diameter of $5 \mathrm{~cm}$. when expanded. At first ovate, becoming campanulate, finally plane, with revolute margin, and splitting longitudinally through gills. Pileus deeply striate radially, except on disk, striae forked. Cells on surface dome-shaped, capitate setae abundant when young. Margin uneven, often oblique. Color of pileus variable, yellowishbrown to reddish-brown, with decidedly darker reddish disk. Stipe 5-12 cm. long, 2-4 mm. thick, glistening white, even, hollow, longitudinally silky-striate, often twisted. Apex minutely pruinose, base with radiating ascending setae (especially evident in culture). Gills narrow, thin, crowded, free, membranous. Cystidia on surface of gills globose to pyriform, $35^{-50} \mu$ across. Basidia two-spored. Spores black in mass, deep chestnut by transmitted light, elliptical, apiculate, $\mathrm{r} 2-\mathrm{I} 5 \mu \times 8.5^{-10} \mu$. Habit gregarious in wild state, caespitose in culture. Occurs on dung hills and heavily manured soil. 
constant in its characteristics. Lange (18) described and named a twospored species which may be allied to our agaric.

The spores of Coprinus ephemerus f. bisporus germinate in five hours or less, in distilled water, Ann Arbor tap water, maltose agar, or horse dung extract agar. The germinating spore does not swell; the single apical germ pore opens with a fimbriate fringe and a globose vesicle appears. A stout germ tube grows from the vesicle, followed by one or more thinner tubes, which appear from the vesicle or from the first germ tube. The mycelium develops rapidly, growing for the most part submerged in the substratum, seldom forming a cottony surface layer. Oidia have not been observed in my cultures of this form. The percentage of spore germination is extremely variable, ranging from 5 to 95 percent. There seems to be no constant relation between the external conditions under which the fruit bodies develop and the percentage of germination. Unexplained irregularity was also found in the length of time elapsing between the button stage and maturity. It was found that even when germinated spores are put into the cold room, at a temperature of $3-5^{\circ} \mathrm{C}$., growth takes place, and fruit bodies develop to complete deliquescence of the pileus.

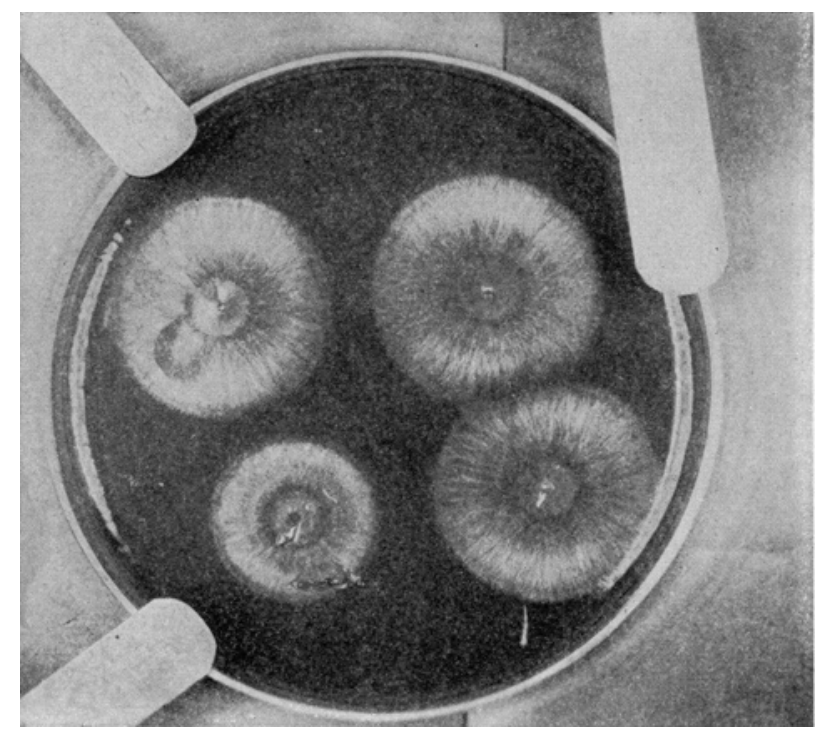

TEXT FIG. 2. Four monosporous mycelia of Coprinus ephemerus f. bisporus, from spores picked at random from a spore deposit. The three large mycelia are in the secondary condition. The small mycelium is a characteristic aberrant haplont.

Clamp connections appear within two or three days on most monosporous mycelia, and within eleven to fifteen days fruit bodies having twospored basidia with fertile spores are produced. These facts indicate that in this form, most, if not all, monosporous mycelia are homothallic. During 
four years of culturing, with repeated re-isolation in monosporous culture, the two-spored character and the sex reactions have remained constant. It was found, however, that all monosporous mycelia do not form clamp connections. In more than two hundred monosporous mycelia, approximately Io percent did not develop clamp connections. Another twelve percent of the mycelia isolated died in a few days. On the assumption that the surviving exceptional mycelia are haploid primary mycelia, they were paired in all possible combinations. The results obtained from these pairings are given in table $\mathrm{I}$. The $(+)$ sign indicates that crossing occurred between two primary mycelia, giving rise to a secondary mycelium which has clamp connections. The (-) sign indicates that no crossing occurred. Fruit bodies were produced on all the secondary mycelia obtained in the matings shown in table I. Spores I and 4 were taken from fruit body No. I9, spores $\mathrm{I} 3$ and $\mathrm{I} 4$ are from fruit body No. 20, and spores $22,23,24,25$, and 26 are from a third fruit body, No. $2 \mathbf{I}$. The vegetative appearance of the haploid mycelium, contrasted with the normal diploid mycelium, is shown in text figure 2.

TABle I. Coprinus ephemerus f. bisporus. Nine Haplonts Paired in All Possible Combinations. Haplonts $I$ and 4 Are from Fruit Body No. I0, Haplonts 13 and 14 Are from Fruit Body No. 20, and Haplonts 22-26 Are from Fruit Body No. 21. Note that 13 Crosses with Five Other Haploid Mycelia.

\begin{tabular}{r|ccccccccc}
- & 4 & 14 & 24 & 22 & 23 & 25 & 26 & $\mathrm{I}$ & $\mathrm{I3}$ \\
\hline 4 & - & - & - & - & - & - & - & - & - \\
14 & - & - & - & - & - & - & - & - & - \\
24 & - & - & - & - & - & - & - & - & - \\
22 & - & - & - & - & - & - & - & - & + \\
23 & - & - & - & - & - & - & - & - & + \\
25 & - & - & - & - & - & - & - & - & + \\
26 & - & - & - & - & - & - & - & - & + \\
1 & - & - & - & - & - & - & - & - & +
\end{tabular}

It is evident that there is no strict segregation into two sexually opposite groups. An interesting feature of table $\mathrm{I}$ is that haplont $\mathrm{I} 3$ enters into the largest number of crosses, and it crosses with haplonts derived from two other fruit bodies. It should further be noted that haplonts 4, I4, and 24, each derived from a different fruit body, do not cross with any haplont used in this table.

The data in table $I$ are too meager to justify an elaborate interpretation. In order to obtain more extensive data on the reactions of aberrant haplonts derived from the same fruit body, 125 germinated single spores were isolated from fruit body No. 25. Of this number of mycelia, 13 remained in the 
primary condition. These haplonts were paired in all possible combinations. The results are given in table 2 . The form of tabulation shown in table 2 is

TABLE 2. Coprinus ephemerus $f$. bisporus. Thirteen Haplonts Derived from Fruit Body No. 25, Paired in All Possible Different Combinations. Haplont 27 Enters into the Largest Number of Crosses. Segregation into Sex Classes is not Evident.

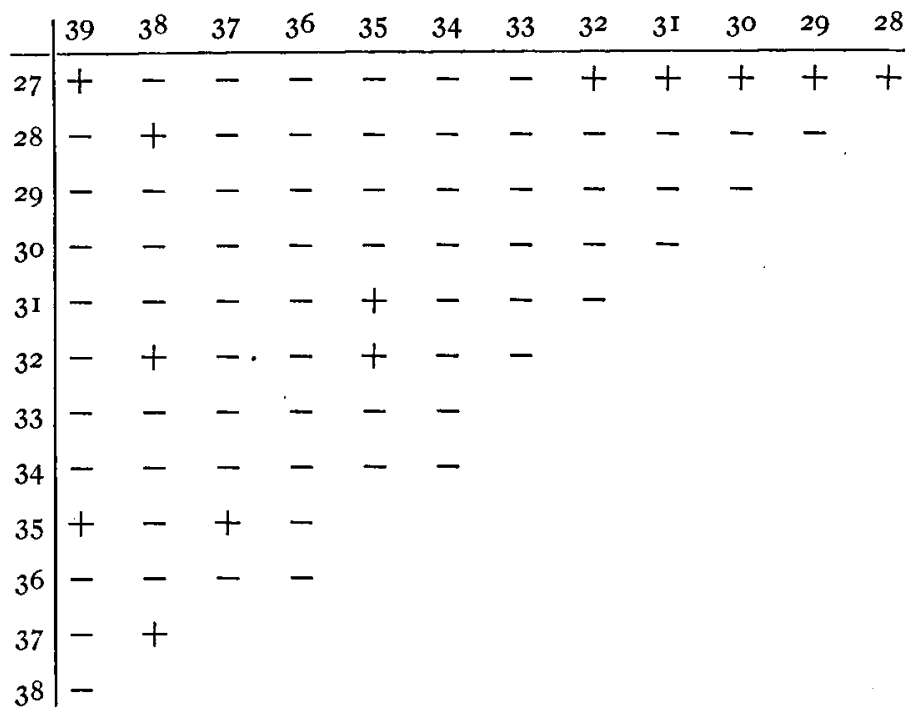

useful in the actual routine of making crosses because duplications and selfmatings are eliminated. 'Since it was so evident from table $\mathbf{I}$ that there are no distinct sex classes, the results were not rearranged into the customary form of tabulation used in such work. Note that haplont 27 enters into a

TABLE 3. Coprinus ephemerus f. bisporus. Four Haplonts Which Seem to be Highly "Fertile," Since They Enter into Many Crosses, Were Paired in All Possible Combinations. Note Apparent Segregation into Two Sex Classes.

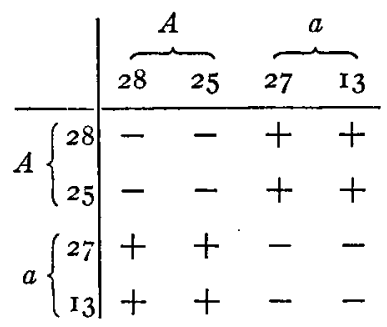

relatively large number of crosses, and that haplonts 33 and 36 do not cross with any haplont of this set. The results given in tables $\mathrm{I}$ and 2 may be summarized as follows:

I. Some of the exceptional haplonts derived from monosporous mycelia are capable of crossing with haplonts derived either from the same fruit body or from other fruit bodies. 
2. Certain haplonts cross with a relatively large number of other haplonts, while some haplonts do not seem to enter into crosses, at least in the pairings which were made.

3. There is no segregation into distinct sex classes.

4. The aberrant haplonts remained viable and in the primary condition for two years.

\section{The Cytology of Coprinus ephemerus $f$. bisporus}

The description of the nuclear cycle in this form may conveniently begin with the hymenium. The basidia originate in a rather deep subhymenial layer of pseudo-parenchymatous cells (Pl. LXIV, fig. 2). The narrow base of the basidium is inserted on an isodiametric cell from which it is always separated by a cross wall. In no case was a clamp connection found at the base of a basidium, or elsewhere in the subhymenial trama. Synkaryons were observed in the subhymenial cells but, as pointed out by the writer (28), nuclear counts in microtome sections of pseudo-parenchymatous cells are rather uncertain.

The young basidia are distinctly binucleate. This is best demonstrated when the two nuclei are about half way up the basidium, lying side by side on a characteristic cytoplasmic bridge (fig. I). Karyogamy occurs at this point and the fusion nucleus moves upward.

Some difficulty was at first experienced in staining certain details of the fusion nucleus. The large nucleolus stains intensely with iron haematoxylin, safranin, or basic fuchsin, but these stains when used with various acid counterstains failed to show well the nuclear membrane and the reticulum. These features were finally demonstrated by the use of the acid haem-alum previously mentioned. In heavily stained preparations the outline of the entire nucleus and indications of a delicate reticulum were unmistakably shown (fig. 2).

In this agaric, the fruit body undergoes considerable growth without any apparent change in the fusion nucleus. Improvements in technique may reveal elaborate pre-meiotic processes during this period. This species belongs to the inaequi-hymeniiferous type (Buller, 4), in which the basidia on a certain area of a gill are in approximately the same stage of development. In a preparation of a cross section through the gills, there may be hundreds of basidia in practically the same nuclear condition. It was necessary to make many fixations to find certain desired stages, since a fruit body may yield material in which the nuclei of all the basidia are in the same stage, but when the desired stage was found, there was a wealth of material available.

In this Coprinus meiosis occurs at definite times and over a brief period, and the process itself probably occurs with some rapidity. Under the somewhat variable conditions in the writer's laboratory, material in meiosis was likely to be found between four o'clock and eight o'clock P.M. No special 
study was made of the effect of external conditions on the time of occurrence of nuclear phenomena in the basidium. Just before meiosis, the nucleolus of the fusion nucleus is relatively large and stains intensely with basic fuchsin. A beak-like projection was frequently observed on the nucleolus at this time (fig. 3). The chromosomes do not appear simultaneously, but arise successively and at random within the nucleus, the outline of which is still evident for some time (figs. 4-7). There are approximately eight to ten chromosomes, and by the time they have all formed the nuclear outline has disappeared (figs. 8-10). The nucleolus progressively decreases in size until it is only about twice as large as a chromosome (figs. 9 and 10). The chromosomes become distributed along a transverse, apical spindle. A deeply stained body, presumably the true nucleolus, is evident, though still further reduced in size, at some distance from the spindle (figs. 9-I3). Finally the chromosomes separate into two groups and each group becomes the locus of the chromatin of a daughter nucleus (figs. I4 and I5).

The two nuclei divide simultaneously in the second division. The spindles are usually obliquely placed in the basidium, and are seldom parallel to each other. No centrosomes were observed in any stage of meiosis, but the nucleolus-like body present in the first division persists through the second division and may be variously placed with respect to the conjugate spindles (figs. I 7 and I8). Four nuclei are finally formed. They are alike in size, visible structure, and staining properties, but their orientation in the basidium is extremely variable. This irregularity in the position of the tetracyte nuclei in the basidium is strikingly evident from the time the nuclei are formed until they begin to migrate into the spores. Soon after meiosis is completed, two conical sterigmata develop on each basidium, and a spore is formed on each sterigma (Pl. LXIV, fig. 20; Pl. LXV, fig. 23).

The migration of nuclei into the spores presented some of the most puzzling phenomena encountered in this study. Certain technical difficulties were also met. The early softening of the pileus in this fungus, apparently the forerunner of autodigestion, makes fixation and preparation of the material uncertain. Furthermore, the spore wall begins to darken early and it becomes quite opaque simultaneously with a complete collapse of the tissues of the pileus. In favorable material, ${ }^{3}$ however, the important features of spore formation and nuclear migration were determined.

As already mentioned, the two sterigmata arise with no apparent relation to the position of the four nuclei in the basidium. No centrosomes or

${ }^{3}$ Cultures were made in pint bottles patterned after a milk bottle and made especially for this department. Soil and dung can be rammed tightly into these heavy bottles and the glass withstands autoclaving. A large cork enveloped in cotton serves as an efficient and easily handled plug. If cultures are kept at a temperature of $5-6^{\circ} \mathrm{C}$., fruit bodies develop slowly; by bringing a culture into a warm room when the fruit bodies are slightly younger than the desired stage, rapid growth is started in a few hours, and fruit bodies can be killed at the proper stage of development. 
kinoplasmic fibrils were observed and the nuclei do not become attached to the apex of the basidium. The spores appear and may attain nearly full size while the nuclei are still variously grouped or scattered, apparently at random, in the basidium (figs. 19-23). On the other hand, nuclear migration may begin while the spores are still relatively small. The nuclei finally approach the sterigmata. In some cases, two nuclei were observed at the base of a sterigma, while in other cases it was equally clear that there was one nucleus at a sterigma and the other three nuclei were some distance away.

The first indication of nuclear migration is a beaked attenuation on one side of the nucleolus toward the sterigma, and a general elongation of the nucleus (fig. 24). The outline of the nucleus disappears and the chromatic material becomes a beaded, elongated body. This passes through the sterigma into the spore and there becomes re-organized into a definite nucleus (figs. 24 and 25).

Since there are four nuclei formed in the basidia of this fungus and each basidium bears but two spores, it was necessary to determine the ultimate disposition of the four nuclei and to determine how many nuclei enter each spore. The evidence obtained by the examination of hundreds of basidia seemed at first to be contradictory. In some basidia that had shed their spores, two residual nuclei were observed, suggesting that one nucleus enters each spore; but most of the basidia on which there were mature spores were devoid of nuclei. Although the spore wall begins to darken before nuclear migration is completed, some good figures were found showing immature spores containing from one to three nuclei (figs. 26-28). Figures showing the migration of a nucleus into a spore that already contained one nucleus were observed (fig. 25). In spite of this latter evidence, the writer would have been reluctant to base an interpretation on cytological data alone. But the data obtained from monosporous cultures and from matings between the exceptional haploid mycelia offer a plausible explanation of the observed irregularities in nuclear behavior. The relation between the described sex reactions of this fungus and the nuclear phenomena will be discussed later.

\section{Nuclear Phenomena of Spore Germination and in the Mycelium}

In material prepared by the centrifuge method, the nuclei in the spore were readily stained and counted. The maximum number of nuclei counted in any one spore was eight. Most of the spores examined contained nearly this number and the spores which contained fewer nuclei appeared to be partly missing, due to the sectioning. Practically the entire volume of the spore is taken up by nuclei. The full number of nuclei in a complete spore cannot be determined with absolute certainty because of inherent limitations of the microtome method, but the results obtained are nevertheless significant. It is safe to infer that the mature spore contains as many as eight nuclei (fig. 29). 
Nuclear phenomena in the germ tube and the mycelium were studied by means of the agar-gelatin film method. The structure of the fixed and stained nucleus in the mycelium may best be described here. The nucleolus stains intensely with iron haematoxylin and in strongly destained preparations only the large nucleolus is evident as shown in figure 38 and others. For certain studies this type of preparation is desirable. By appropriate differentiation the entire nucleus can be stained in some detail (figs. $3 \mathrm{I}, 32$, 35). Irregularities in the thickness of the matrix influence the rate of destaining and afford delicate gradations of differentiation. The nucleus occupies practically the entire diameter of the hypha. Within the nucleus there are, in addition to the large nucleolus, an undetermined number of minute, lightly stained, but distinct granules. No indications of a reticulum were observed. The above description applies to the nuclei in mycelium that is growing slowly and in which the nuclei presumably are not undergoing rapid division.

In rapidly growing mycelium, especially in cells near the ends of the hyphae, only the nucleoli can be stained effectively. They appear as large deeply stained chromatin bodies. In preparations of such material many of these chromatin bodies appear to be in stages of constriction and attenuation (fig. 44). My figures resemble illustrations by Miss Nichols (26), Kniep (I7), Mlle. Bensaude (2), and others. These nuclear figures probably represent a form of mitosis which occurs with some rapidity, and the details of which are beyond the resolving power of present optical equipment.

The initial vesicle as it appears from the germ pore contains progressively from one to four nuclei, before the germ tube proper appears. As the germ tube and lateral branches develop the nuclei increase rapidly in number. The largest number of nuclei observed in an unbranched tube was seven (fig. 32), and in a branched but apparently non-septate tube sixteen nuclei were counted (fig. 33). Cross walls are rather difficult to demonstrate. If the fixation produces no shrinkage the cross walls may not be visible in a germ tube of given length; but a tube of comparable age can be shown to be distinctly septate if the drying of the film is gauged to produce a very slight degree of shrinkage, for the cytoplasm is thus pulled away from the walls making the cross walls visible. This treatment does not injure the staining properties and it greatly facilitates the accurate counting of nuclei (fig. 35).

Cross walls appear earlier than has been generally believed. Figure 35 shows a relatively young germ tube in which an end cell containing seven nuclei has been separated from the vesicle by a cross wall. A new hypha containing two nuclei has grown from the vesicle, which now contains seven nuclei. Figures 30 to 44 show various stages in the early growth of the mycelium and the formation of septa. Special attention was given to the development of side branches in order to determine how many nuclei enter a branch before its basal septum is laid down. In C.ephemerus f. bisporus a 
branch may contain from four to ten nuclei before the cross wall appears. It is certain that several nuclei may move into the branch from the main hypha and these nuclei undergo division in the branch.

In the terminal cells of slowly growing mycelium as many as ten large "resting" nuclei have been observed. In actively growing terminal cells, over twenty-five small chromatin bodies, presumably rapidly-dividing nuclei, have been counted. Short uninucleate intercalary cells are common in the older mycelium and the number of nuclei in intercalary cells ranges up to five or perhaps more.

The essential facts of the cytology of the germ tube and young " primary" mycelium of Coprinus ephemerus f. bisporus may now be summarized:

I. The cells are mostly coenocytic, containing from one to twenty-five nuclei.

2. Synkaryons are not in evidence and the several nuclei in a cell may divide independently of each other. The apparent pairing of nuclei is interpreted as being the result of nuclear division, rather than of nuclear association.

3. Clamp connections are lacking and cross walls are formed independently of nuclear phenomena.

Since Coprinus ephemerus f. bisporus is usually homothallic, it is of interest to trace the development of the binucleate secondary condition from the coenocytic germ tube. About forty-eight hours after the germination of a spore the mycelium has attained considerable size, forming a circular weft $.5 \mathrm{~mm}$. or more in diameter, consisting of elaborately anastomosed hyphae. The hyphae are more or less irregular and contorted, the branching is abundant and also irregular, and there are no clamp connections. These features are characteristic of primary mycelium. The primary condition is of short duration. In most cultures, after forty-eight hours, a few clampbearing hyphae appear on the periphery of the culture. If a culture happens to be examined at the proper time, it is possible to find a condition in which there is only a single secondary hypha on the entire margin. Other secondary hyphae appear later at various points on the margin of the same mycelium. These hyphae are easily recognized because they are strikingly straight and have sparse branches at regular intervals, and of course have clamp connections. The secondary hyphae grow so much more rapidly than the primary hyphae that after three to four days the growing margin of the culture consists entirely of secondary hyphae.

Single-spore cultures ranging in age from twelve hours to four days were studied cytologically. It was found that the coenocytic condition soon passes over into a uninucleate condition. By a more or less delayed formation of cross walls, the cells of the coenocytic primary mycelium become uninucleate (figs. 45, 46). The uninucleate primary condition is then replaced by the secondary, clamp-bearing condition. In stained preparations the secondary hyphae may be readily located, even before they have emerged very far 
beyond the marginal primary hyphae (PI. LXVI, figs. 47 and 50). It is possible to trace the secondary hyphae back some distance into the culture, but the actual origin of a secondary hypha was always obscured in a weft of highly anastomosed primary hyphae near the center of the culture.

After the secondary condition is established the mycelium bears clamp connections and all the cells of the secondary mycelium are binucleate. This fungus does not seem to be a favorable subject for a critical study of the details of conjugate mitosis, but many good figures were obtained showing the essential features of clamp formation. The process in this form agrees in salient points with the interpretations of Mlle. Bensaude (2) and Kniep (I4). A short, slender branch grows from the terminal cell and curves back until it touches the main hypha. A minute deeply staining body was frequently observed in the tip of the recurved clamp hypha. The two nuclei of the terminal cell lie near the point of origin of the clamp (fig. 48). These nuclei undergo conjugate mitosis; one spindle lies partly within the clamp hypha and the other one in the main hypha (figs. 49-50).

Each daughter nucleus is first evident in telophase as a deeply staining body which apparently becomes the nucleolus of the "resting" nucleus (fig. 49). A transverse septum now separates the two daughter cells and an oblique septum separates the clamp connection from the end cell. The passing of the daughter nucleus from the clamp hypha into the penultimate cell is somewhat delayed but this finally occurs and each daughter cell becomes binucleate. The secondary mycelium of Coprinus ephemerus $\mathbf{f}$. bisporus is thus characterized by:

I. The presence of clamp connections and synkaryons.

2. Conjugate division of the synkaryons associated with the formation of clamp connections.

3. The formation of fruit bodies.

The foregoing description of nuclear phenomena in the mycelium takes no account of the occurrence of occasional mycelia that remain primary. These exceptional mycelia cannot be definitely identified as such until four or five days after germination of the spore. In a few rare cases the appearance of clamp connections on diploid mycelia was somewhat delayed, but since the cultures were examined frequently these cases were found and properly classified in due time. The mycelia which remained primary and viable were examined cytologically. It was found that the cells of this type of mycelium are uninucleate (fig. 5I), apparently resembling those "primary" homothallic mycelia from which secondary hyphae have just appeared.

Nuclear phenomena in the heterothallic mycelia after the permanent establishment of the primary condition are easy to determine but the origin of these exceptional haploid mycelia is not clear. The writer has pointed out the limitations of the microtome method which was necessary for the study of mature spores. In stained preparations of germinated spores, 
hundreds of germ tubes were examined and the coenocytic condition was observed in all cases. Evidently the data on nuclear number in the spore and germ tube offer no clue to the origin of the exceptional heterothallic mycelia. It appears from the available evidence that in Coprinus ephemerus f. bisporus, homothallic and heterothallic mycelia arise from respective germ tubes that are similar in appearance and in the number of nuclei, if not in the kind of nuclei, which they contain. Both types of mycelium progress from a coenocytic to a uninucleate primary condition. During the primary condition, in most mycelia, secondary hyphae with binucleate cells and clamp connections arise within an anastomosed hyphal weft, whereas some mycelia remain in the primary condition and react as haplonts in certain matings.

\section{Coprinus ephemerus Fr. (Four-spored)}

The four-spored form of Coprinus ephemerus is perhaps the most common dung-inhabiting Coprinus occurring in southeastern Michigan. It has appeared on practically every collection of horse-dung made by the writer. Isolations were made from a number of wild-growing fruit bodies. There were some variations among the fruit bodies that appeared in culture, suggesting that there may be more or less distinct strains of this form. A strain which was designated as Strain 7 is practically indistinguishable from the two-spored form under consideration in this work. Certain features of the nuclear cycle and sexuality of this four-spored form (Strain 7) are introduced here for comparison with the two-spored form.

Monosporous isolations of Strain 7 were made from fruit bodies that had appeared in pure culture. It was found that monosporous mycelia do not produce clamp connections or fruit bodies. These monosporous mycelia have the characteristics of primary mycelium, the cells are uninucleate. there are no clamp connections at the septa, and the branching is irregular, Matings were made between monosporous mycelia and in certain combinations clamp connections appeared. The clamp-bearing mycelium was found to be in the secondary condition, the cells are binucleate, the branches occur at regular intervals, and fruit bodies arise from the mycelium. The type of result obtained in matings is characterized by table 4. Monosporous mycelia fall into one of two sexual strains and clamp-connections appear in any cross between two sexually opposite strains.

Mature spores from completely deliquesced fruit bodies were imbedded en masse and sectioned. It was found that the mature spores are binucleate (fig. 52). In occasional spores three nuclei were observed, but this may be interpreted as a precocious division of one nucleus in the spore. It has already been mentioned that the primary mycelium has uninucleate cells (figs. 54-56). The secondary mycelium bears clamp connections and the cells are binucleate. Karyogamy occurs in the basidium and the fusion nucleus undergoes meiosis, producing four nuclei (fig. 57). The basidium 
bears four spores and each spore receives one nucleus. This nucleus divides once, making the mature spore binucleate.

Table 4. Coprinus ephemerus Fr. (Four-spored). Six Monosporous Haploid Mycelia Paired in All Possible Combinations. Segregation into Two Sex Classes is Obvious

\begin{tabular}{|c|c|c|c|c|c|c|c|}
\hline & & & & \multicolumn{3}{|c|}{$A$} & \\
\hline & & 6 & 2 & I & 3 & 4 & \\
\hline & & - & - & + & + & + & \\
\hline & & - & - & + & + & + & \\
\hline & & + & + & - & - & - & \\
\hline & & + & + & - & - & - & \\
\hline & & + & + & - & - & - & \\
\hline & & + & + & - & - & - & \\
\hline
\end{tabular}

The facts brought out in this study of the comparative cytology and sexuality of the two-spored and four-spored forms of Coprinus ephemerus will bear amplification by the study of other genera before one undertakes a broad interpretation of the data. The Coprini are a peculiarly distinctive group, characterized by an evanescent fruiting stage, and in such organisms one is more likely to expect aberrations from the usual nuclear phenomena. For this reason an extensive search was made in other genera for evidence bearing on the phenomena found in the Coprini under investigation. In the following pages we shall consider the life cycles of other agarics which have a bearing on this problem.

\section{Naucoria semiorbicularis Fr. forma bispora, forma nov. ${ }^{4}$}

This agaric occurs in late summer and fall in southeastern Michigan. It is rather uncommon, appearing during rainy weather, mostly on pastures and lawns. No record of a two-spored form was found in the literature. Bauch (I) whose list of known two-spored hymenomycetes is the best to date, did not mention the form. The present writer has found, in two years, only five fruit bodies with two-spored basidia. These fruit bodies were found on lawns on which many fruit bodies with four-spored basidia were collected.

The spores of the two-spored form germinate in a few hours on maltose agar or horse dung extract agar. Single-spore isolations were made from a fruit body, but due to the contaminated condition of the single fruit body

4 Pileus $1-2.5 \mathrm{~cm}$. broad, hemispherical, surface glabrous; viscid when moist, rimose when dry. Margin even; flesh thick on disk, thinner toward margin, ash gray. Pileus golden yellow to ochraceous, darker on disk. Stipe $3-6 \mathrm{~cm}$. long, $\mathrm{I}-3 \mathrm{~mm}$. thick, pale ochraceous, terete, rigid, equal, stuffed, silky-fibrous, glabrous. Gills broad, adnate, close, rusty-brown when mature. Edge of gills fimbriate, whitish. Sterile cells on edge of gills capitate to flask shaped. Basidia two-spored. Spores rusty-brown, elliptical, $13-16 \mu$ $\times 8$-ाo $\mu$. Habit scattered solitary, on lawns, open grassy places. 
available for this purpose, only nine mycelia were isolated in pure culture. Because of the characteristic appearance of the spore there is no doubt as to the single-spore origin of the cultures obtained. In all of these cultures clamp connections appeared within four days after spore germination. Before the appearance of clamp-bearing hyphae, the mycelium has all the external characteristics of the primary condition, the hyphae are crooked and irregularly branched and there is extensive anastomosing. The clampbearing hyphae are easily recognized as soon as they emerge beyond the margin of the mycelial cushion. These hyphae are strikingly straight, the branches occur at more or less regular intervals, and clamp connections are present. A day or two after the appearance of the secondary hyphae, the periphery of the mycelium is in the secondary condition and this condition is permanent. The foregoing data indicate that Naucoria semiorbicularis $\mathrm{f}$. bispora is probably homothallic, but in view of the results obtained in Coprinus ephemerus $\mathrm{f}$. bisporus, it is unsafe to assert on the basis of cultural data alone, that our Naucoria is regularly homothallic.

Nuclear phenomena during spore germination and during the development of the mycelium closely parallel the condition found in Coprinus ephemerus $\mathrm{f}$. bisporus. In the mycelium of Naucoria semiorbicularis $\mathrm{f}$. bispora the staining properties of the nuclei are more favorable than in any species studied by the writer. Preparations show nuclear structure in good detail, considering the subject. The germ tube is coenocytic and contains a large number of well defined nuclei (fig. 64). Cross walls appear first near the large vesicle (fig. 65) and additional walls are formed progressively farther away from the vesicle. Within two days after the germination of the spore the cells of the mycelium become binucleate, except for the end cells which are coenocytic. As already mentioned in connection with Coprinus, the apparently multinucleate condition of end cells may be merely due to the difficulty of demonstrating cross walls in actively growing hyphal ends.

In stained preparations the new clamp-bearing hyphae are very evident, projecting out beyond the margin of the mycelium. The clamp is characterized by an unusually long loop. The cells are binucleate and conjugate mitoses of the synkaryons are associated with clamp formation, proving that these hyphae are in the diploid, secondary condition. If preparations are killed at the time when the secondary hyphae first appear on the margin of the culture, these hyphae can be traced back into the mycelium for some distance, but the point of origin of the secondary hyphae was not definitely found. As in our two-spored Coprinus, the secondary condition arises in a weft of anastomosing haploid hyphae.

Nuclear behavior in the hymenium of Naucoria semiorbicularis $\mathrm{f}$. bispora conforms in general to the condition found by the writer in Coprinus ephemerus f. bisporus. The basidia are at first binucleate and karyogamy takes place (fig. $5^{8}$ ) followed by two nuclear divisions. A striking feature at this stage is that the tetracyte nuclei are far down in the basidium (fig. 59). The 
technique used by the writer failed to show any connection between the nuclei in the basidium and the two sterigmata. Furthermore, the nuclei have no definite orientation in the basidium at any time prior to the beginning of migration into the spores. In the limited amount of material available for sectioning, nuclear processes probably were not going on rapidly because very few figures of meiosis or nuclear migration were found. There is no reason to believe that these phenomena in our Naucoria differ radically from the preceding cases described.

Due to the comparatively firm texture of the fruit bodies and of the hymenium, this material was favorable for the observation of certain features which were not readily seen in the more evanescent agarics studied. During the process of making cytological preparations, the old basidia remained sufficiently intact to show well their contents. Many excellent figures were obtained of old collapsed basidia, from which the spores had no doubt been shed. We cannot state, of course, how many viable spores were shed by any given basidium, nor how many nuclei were present in any of the spores. There seems to be little doubt that some of the collapsed basidia contain two residual nuclei (figs. 6o, 6I). Other collapsed basidia were obviously quite empty. These observations show that at least in some basidia the four tetracyte nuclei may be distributed to the two spores, whereas, in other basidia, two nuclei may remain behind.

The limited amount of material available did not permit the use of the mass imbedding method for the study of nuclear number in the spore, but the wall of the immature spore is sufficiently translucent to permit certain observations to be made. Two large nuclei were observed in large, thickwalled, but transparent spores (fig. 62). In older spores, having darker colored walls, four smaller and less clearly defined nuclei are usually present (fig. 63). Beyond this point the data are uncertain because the spore walls become dark and there are too few sectioned spores in our preparations to make further estimates.

\section{Galera tenera Fr. forma bispora, forma nov. ${ }^{5}$}

This two-spored form first came to the writer's attention in a local greenhouse, where it appeared on heavily manured flower benches during four successive winters. The four-spored form was also present and only by examination of the basidia was it possible to distinguish between the two forms. In the field the two-spored form is rather rare. It has been collected on lawns and in pastures, where it was always found in association with the more abundant four-spored form. Pure cultures were made from spores of

5 Pileus $1.5-3 \mathrm{~cm}$. broad, conic-campanulate, striatulate-hygrophanous when moist, atomate when dry. Flesh submembranous corticated. Pileus grayish-ferruginous when moist, creamy white when dry. Stipe 6-10 cm. long, 1-1.5 mm. thick, hollow, equal, fragile, pruinose at apex, white to creamy-white. Gills narrow adnate, sub-distant. Sterile cells on edge of gills capitate, $\mathrm{I}^{-18 \mu} \times 7^{-8} \mu$. Basidia two-spored. Spores ochre, elliptical, apiculate, $12.5-16 \mu \times 7.5-9 \mu$. Habit gregarious, on lawns, pastures, dung hills. 
both forms. The spores of the two-spored form germinate in a few hours on dung agar. The mycelium grows slowly, doing best on cow-dung agar and on sterilized cow dung. No fruit bodies have as yet appeared in culture, although some cultures are three years old. Practically no work has been done to determine the physiological factors necessary to stimulate fruiting.

Most monosporous mycelia develop clamp connections, which appear early, usually at the very first septum which is formed in the germ tube (Pl. LXVII, fig. 75). The initial vesicle frequently has two germ tubes growing out of it (fig. 77). These clamp-bearing mycelia are in the secondary condition, and being of monosporous origin, they may be considered homothallic. Oidia were not found on secondary mycelia. The mortality among germinated spores was rather high. Of 200 isolations, I 49 mycelia grew well and became secondary, 42 died soon after germination, and 9 others grew but did not develop clamp connections. These latter mycelia, some of which produced oidia, were apparently in the primary condition and to test this assumption, pairings were made in all possible combinations. In a few matings, as shown in table 5, crossing occurred and clamp connections appeared in the new mycelium. The results indicate that there is no segregation of mycelia into distinct, sexually opposite groups. Unfortunately, the number of viable primary mycelia available was too small to justify a more elaborate factorial explanation of sexuality. Nevertheless the primary nature of the exceptional mycelia is clear, and the data from the reactions in this form support the evidence obtained from Coprinus ephemerus f. bisporus.

Table 5. Galera tenera f. bispora. Nine Aberrant Haplonts of Monosporous Origin Paired in All Possible Different Combinations. Only Two Crossings Occurred

\begin{tabular}{|c|c|c|c|c|c|c|c|c|}
\hline & | 19 & 18 & 17 & 16 & 15 & I4 & I3 & \\
\hline$\overline{I 0}$ & - & - & + & - & - & - & - & - \\
\hline 12 & - & - & - & - & - & + & - & \\
\hline I3 & - & - & - & - & - & - & & \\
\hline $\mathrm{I}_{4}$ & - & - & - & - & - & & & \\
\hline I5 & - & - & - & - & & & & \\
\hline 16 & - & - & - & & & & & \\
\hline $\mathrm{I} 7$ & - & - & & & & & & \\
\hline 18 & |- & & & & & & & \\
\hline
\end{tabular}

A cytological examination of Galera tenera f. bispora was made. The secondary mycelium is diploid, the cells are binucleate after the formation of the first septum in the germ tube, and clamp connections are formed thereafter at each septum. The secondary, diploid condition is thus evident in the germ tube and may become from that point a fixed characteristic of the mycelium. Although hundreds of stained germ tubes were examined, 
no evidence was found concerning the origin of the exceptional primary mycelia. This does not exclude the possibility that uninucleate mycelia were overlooked nor the possibility that the aberrant primary condition originates somewhere in the mycelial weft developed from the germ tube. However, it was found that mycelia which are permanently primary have uninucleate cells and are therefore haplonts (fig. 78). This fact confirms the evidence obtained by making pairings of the exceptional mycelia.

Since fruit bodies were not obtained in pure culture it was necessary to use wild fruit bodies for the cytological study of the hymenium. Objections to the use of wild fruit bodies for cytological and genetic work in certain forms were stated earlier in this paper. These objections are not as serious in the case of Galera tenera f. bispora as in Coprinus ephemerus f. bisporus. The fruit body of this Galera belongs to the aequi-hymeniiferous type, in which any small area of a gill bears basidia of various ages. Mature spores and very young basidia occur within a few microns of each other and it is therefore not necessary to use small button stages to obtain young basidia. By using fully expanded and developed fruit bodies, it was possible to determine accurately the specific identity as well as the two-spored character before killing the material.

The young basidium is binucleate and karyogamy occurs. The fusion nucleus is large and well defined, having a large lenticular nucleolus and readily stainable chromatic reticulum (fig. 66). Chromosomes have been demonstrated in pre-meiotic stages and in meiosis, but due to the presence of numerous deeply staining granules in the cytoplasm, at least with the fixations used, chromosome counts would be of doubtful accuracy in this form. However, the presence of synkaryons and the occurrence of karyogamy indicate the diploid condition. Two nuclear divisions in the basidium give rise to four nuclei which seem to be alike in size, structure, and staining properties.

Migration of nuclei into the spores was demonstrated much more readily in this Galera than in the preceding Coprinus, because the fruit body of the Galera is not as evanescent, and migration can be studied in a fruit body which is still young and firm enough to imbed properly. Prior to the formation of the sterigmata the four nuclei in the basidium have no definite arrangement. As the sterigmata and spores develop the nuclei move upward in the basidium, but at no time do they become attached to the upper wall. Two of the nuclei prepare to undergo migration, one nucleus moving into the broad base of each sterigma. The nuclear membrane disappears and the stainable material becomes localized in the nucleolus (probably a karyosome). A pronounced beak appears on this chromatin body (fig. 68). Finally the chromatin becomes attenuated into a beaded filament which passes into the spore (fig. 70).

While one nucleus is undergoing migration into a spore, a second nucleus approaches the base of the same sterigma. The nuclear membrane dis- 
appears (figs. 69-7I) and this second nucleus passes into a spore. It is not difficult to find many figures showing a nucleus in some stage of migration into a spore which already contains one nucleus (figs. $7 \mathrm{I}-72$ ). In this agaric, as in the forms described in the preceding pages, there are clear cut cases of residual nuclei in old basidia that had obviously shed their spores. Occasionally but one nucleus is left in a basidium. Other old basidia certainly are quite empty. The spores progressively contain from one to four nuclei. Thick-walled, dark spores that are apparently mature usually contain four nuclei, as shown in figure 74 , but it should again be emphasized that nuclear counts in sectioned spores should be accepted with reservations.

The cytological and genetical evidence from Galera tenera f. bispora supports the evidence obtained from the study of Coprinus ephemerus $\mathrm{f}$. bisporus and Naucoria semiorbicularis f. bispora. The cytological data on the three forms suggest various ways in which the four nuclei in the basidium may be distributed to the two spores:

I. A spore may receive two nuclei which divide once, making the spore four-nucleate.

2. A spore may receive one nucleus which divides once, making the spore binucleate.

3. A spore may receive one nucleus, and two nuclear divisions occur in the spore, making the spore four-nucleate.

4. The two spores on a basidium may not receive the same number of nuclei, and these two spores, when mature, may or may not contain the same number of nuclei.

The four-spored form of Galera tenera conforms to the typical diploid heterothallic cycle shown in Scheme I. Good preparations of germinating spores were obtained by the agar-gelatin film method. The germ tubes become septate and uninucleate soon after emerging from the spore. The sex-reactions of this form were not determined.

\section{Discusston}

\section{Taxonomic Considerations}

A number of agarics having two-spored basidia have been set up as species. Atkinson (see Lewis, 2I) described Amanita bisporigera Atk., pointing out its close resemblance to $A$, verna Bull. Lange (18) described Coprinus bisporus, which is evidently in the ephemerus group of Coprinus. Bauch (I) suggested that in the case of Hygrophorus virgineus (Wulf) Fr., the two-spored plants comprise a "race" of the four-spored species. The present writer has shown that in a.number of species there are two-spored and four-spored plants, occurring in the same habitat, indistinguishable except for the spore character, and in a Coprinus breeding true for the spore character. This condition was found by the writer in Coprinus ephemerus, Naucoria semiorbicularis, Galera tenera, and Collybia cirrhata. Only twospored fruit bodies of Hygrophorus borealis var. sub-borealis, Stropharia 
umbonatescens, and Typhula sp. were collected. The writer (28) has also studied the cytology of two-spored cultivated plants of Psalliota campestris Fr., a species in which the wild-growing fruit bodies are generally fourspored.

In each of the first four cases mentioned, and in Psalliota campestris, it seems that we are dealing with very closely related two-spored and fourspored plants. It is proposed that in such clear cut cases the two-spored plants be considered a "form" of the species and that the trinomial designation be applied as previously used in this paper. The term "form" implies that morphological characteristics are the basis of the category, and is therefore preferred to terms like "race" and "strain" which have been used with physiological implications. Field studies on Hygrophorus borealis var. sub-borealis, Stropharia umbonatescens, and our Typhula have not been sufficiently extensive to show whether the respective four-spored forms occur. If further field studies show that in any considerable number of agarics there are two-spored and four-spored forms, it may be desirable to consider Atkinson's Amanita bisporigera to be a "form" of Amanita verna Bull.

\section{Salient Morphological and Cytological Features of the Agarics Investigated}

In the three species studied, the subhymenial trama is distinctly pseudoparenchymatous and the basidia were found to originate rather deep in the trama. It is interesting to note that clamp connections were not found in this tissue, and in particular, a clamp connection was never found at the base of a basidium. A similar condition was reported in Psalliota campestris by Hirmer (II) and the writer (28). The lack of clamp connections in the pileus seems to be characteristic in forms having a pseudo-parenchymatous trama. Clamp connections were found in a hypochnoid type (Hypnochnus subtilis Schroet.) by Harper (Io), and the writer has observed clamp connections in the trama of a Typhula in which this tissue is loosely filamentous. Kniep (I3) figured clamp connections at the base of the basidium and in the distinctly filamentous subhymenial tissues of Armillaria mucida Schrad.

The clamp connection is a device to permit a side-by-side orientation of two conjugate spindles, and thereby bring two non-sister nuclei into each of the two daughter cells. In large pseudo-parenchyma cells there appears to be no space limitation on the orientation of the conjugate spindles and therefore the clamp connection does not seem to be a mechanical necessity. Since serial sectioning of pileus cells is scarcely possible, and nuclear counts in individual sections of pseudo-parenchyma cells are unreliable, there remains in some species a gap in our knowledge of the nuclear cycle, between the formation of the fruit body primordium and the differentiation of the hymenium. However, the occurrence of clamp connections in the fruit body tissues in very remotely related genera (Hypochnus, Armillaria, Typhula), suggests that during the formation of fruit body tissues and the organization of the young hymenium there is no significant divergence from the nuclear behavior observed in the vegetative mycelium. 
The difficulty experienced in demonstrating nuclei in the pileus and in old vegetative mycelium in certain species, supports a suggestion made by Mlle. Bensaude (2) and reaffirmed by the writer (28), that in "old" mycelium, in which nuclear division or fusion is not taking place, but in which other cell processes are nevertheless active, the nuclear material is not readily stainable. Further evidence in favor of this view is found in the staining reactions of other fungous tissues.

The writer has observed a similar condition in several rusts. On the margin of the zone of infection the hyphal tips stain deeply and the nuclei can be sharply differentiated out. From this region inward, toward the center of the infection, the hyphae can be stained but the nuclear staining is unsatisfactory. But at the base of the pustule, especially the aecium, there is a sharp transition, the subhymenial and hymenial cells take up stain with avidity, and excellent differentiation of nuclear detail is possible. Between the hymenium and the vegetative hyphal tips there is evidently a zone differing markedly in certain properties. This zone has been considered "old" mycelium in which the protoplasts are in a condition of senility. But it is obvious that this region is inactive only in so far as karyokinetic processes are concerned, because rapid translocation of food to the fruiting region is certainly going on. Furthermore, the primordia of fruit bodies arise from strands of the so called "old" mycelium.

The intense staining of meristematic cells and sex cells has been attributed to the fact that these cells are rich in protoplasm. This explanation is not adequate because in strongly differentiated preparations in which the cytoplasm is completely decolorized there is a marked difference between the staining properties of nuclei in the special cells in question, and in the nuclei of "inactive" cells. There must be a pronounced difference between the chemical or physical properties of the nuclear material in vegetative cells and that of gonotoconts and meristematic cells.

The structure of the fusion nucleus deserves some mention at this point. It was shown that in Galera tenera f. bispora and in Naucoria semiorbicularis f. bispora, the chromatic reticulum of the fusion nucleus is readily demonstrated and that chromosomes arise simultaneously on the reticulum. But in Coprinus ephemerus f. bisporus the nucleolus is exceptionally large and stains intensely, while the reticulum and spireme are barely discernable. Two alternative suggestions are offered in explanation of this condition. The chromatin from which the chromosomes are eventually formed may be distributed on an achromatic framework, but during the early premeiotic phases the chromatin may not be in a readily stainable condition. This view is supported by the observed variations in staining reactions of the nuclei in different phases of the nuclear cycle.

The second possibility is that the chromatin may be localized or stored in the large nucleolus-like body, the achromatic framework in the meantime 
retaining its morphological identity. In this case the nucleolus-like body may be considered to be karyosome, from which the stored chromatin is passed into the achromatic framework during premeiotic processes. The "storage" hypothesis is supported by the following evidence in Coprinus ephemerus f. bispora:

I. The relatively large size and basophilic staining of the karyosome, just before meiosis.

2. The progressive decrease in the size of the karyosome during the formation of chromosomes.

3. The presence of beaked, attenuated projections on the karyosome during pre-meiotic phases.

4. Finally the expulsion, from the chromosome group, of a minute chromatic body, probably the true nucleolus, just before spindle formation.

Meiosis in the two-spored forms presents no features of theoretical importance, largely because the process is not well understood. The chromosomes are so near the limits of good microscopic resolution that a discussion of chromosome structure is out of the question and even chromosome counts are only approximations. An understanding of the mechanism by which the formation of sterigmata is initiated, and by which the nuclei are distributed to the spores, would aid materially in the interpretation of certain subsequent phenomena. The writer's preparations do not show centrosomes. The formation of sterigmata is initiated without any apparent connection with formed bodies in the basidium and the tetracyte nuclei have no evident connection with the spores. Maire (22), Levine (20), and others have figured centrosomes and astral rays in meiosis, and the tetracyte nuclei were figured to be connected to the sterigmata and to the spores by kinoplasmic fibers. The more recent workers, Kniep (I3) and Bauch (I), did not figure centrosomes or fibrils. Kühner (17) figured centrosome-like bodies but he was not certain of the true nature of these bodies.

By way of comparison, I have made a few limited observations on agarics other than those specifically discussed in this paper. In a four-spored, homothallic strain of Coprinus sterquilinus Fr. I have found that before the appearance of sterigmata, the tetracyte nuclei are appressed to the upper wall of the basidium. This condition was not found in any of the twospored or four-spored forms considered here.

In a previous study and in the present work I have failed to demonstrate an organized mechanism controlling the formation of sterigmata or controlling the distribution of the four nuclei to two spores. In view of the known diversity in the staining properties of various agarics, it is possible that the species in which other workers have reported the structures in question are more suitable for demonstrating these structures than my material. It seems desirable at least in the agarics studied by the writer to ignore centrosomes and kinoplasmic fibers either as morphological features or as active factors in the phenomena under discussion. 
The indefinite and variable distribution of tetracyte nuclei in the basidium in my material is very striking. The first semblance of definite orientation becomes evident when two nuclei crowd into the base of a sterigma, and there are explainable exceptions to this behavior. It appears from the evidence presented that the movements and ultimate distribution of the tetracyte nuclei of the basidium are not as rigidly controlled by an established mechanism as has been generally believed.

\section{Factorial Interpretation of Sex on the Basis of Mating Reactions}

Miss Newton (25) has shown that Coprinus Rostrupianus is heterothallic and bisexual. In this species sex is assumed to be determined by one pair of Mendelian factors. This seems to be the situation in my strain of the four-spored form of $C$. ephemerus. Table 4 is representative of the results obtained by mating monosporous haplonts of this form. It is evident that there are but two sex classes. In monosporous mycelia of Galera tenera (4-spored), the cells are uninucleate from the time of germination, and this condition persists for at least a year. The mycelium does not grow well enough in culture to make extensive mating experiments, but the cytologica observations indicate clearly enough that monosporous mycelia are haplonts and that therefore this form is heterothallic. The reactions of the fourspored form of Naucoria semiorbicularis were not determined.

In the two-spored forms studied by the writer, we may consider an interpretation of their sex reactions on the basis of genetic factors. The twospored forms of Coprinus ephemerus, Galera tenera, and Naucoria semiorbicularis, respectively, are normally homothallic. For the present moment we need to consider only the assumption that in these forms the spore normally receives a full complement of whatever sex factors are necessary to establish the diploid (secondary) condition. I have shown that in Coprinus ephemerus f. bisporus and Galera tenera f: bispora, exceptional haplonts of monosporous origin occur.

The aberrant haplonts of C.ephemerus f. bisporus cross in certain matings, as shown in table $\mathbf{I}$. While it is evident from table $I$ that there is no segregation into distinct sex classes, we may test various factorial hypotheses. Let us provisionally assign to mycelium No. I 3 the factor $(A)$. Then mycelia nos. $22,23,25,26$ and I must be given the factor $(a)$, and nos. 4,14 and 24 , the factor $(A)$. But mycelia nos. 4, 14, and 24 do not cross with 22, 23, 25, 26 , and I, although the two groups presumably carry opposite factors. Evidently we cannot explain the reactions on the basis of one pair of factors $(A a)$ in this case.

If sex is determined by two pairs of factors $(A a B b)$, haplonts may carry any one of the following sets of factors, $(A B),(a b),(A b)$, or $(a B)$, and crossing occurs only between two mycelia having no factors in common. To test this hypothesis, we may assign the factors $(A b)$ to No. I3 in table I. Then any haplont with which No. I3 crosses, for instance No. 22, can have 
only the factors $(a B)$. Since No. $22(a B)$ does not cross with No. 4 , the latter may have, on the basis of failure to cross, the factors $(A B),(a B)$, or $(a b)$. Considering on the other hand the fact that No. I3 $(A b)$ does not cross with No. 4 , the latter may have the factors $(A B),(A b)$, or $(a b)$, since in any case $\mathrm{I} 3$ and 4 would have at least one factor in common. It seems that the factors of 4,14 , and 24 cannot be determined on the basis of their failure to cross with a haplont of assigned constitution. The final test would be a positive reaction with some haplont having known (assigned) factors. Hanna (8) has shown that in C. lagopus mycelia from different fruit bodies are mutually interfertile: This does not seem to be the case in my material.

Table 2 indicates the absence of clear-cut sex classes. In one set of matings made between haplonts from tables $\mathrm{I}$ and 2, the results were rather surprising. The haplonts apparently fell into two sex classes as shown in table 3 , but in view of the results shown in tables $\mathrm{I}$ and 2, it is possible that the reactions in table 3 may be due to a chance selection of haplonts, the reactions of which happen to conform to this simple scheme.

A limited number of pairings were made between aberrant haplonts of Galera tenera f. bispora, with the results given in table 5. The striking feature of this table is the small number of crossings obtained. It is obvious that we cannot even begin to formulate a factorial interpretation of the reactions obtained. Repeated examinations of the cultures of haplonts of C. ephemerus f. bisporus and $G$. tenera f. bispora have shown that the primary condition of the exceptional haplonts is permanent. This was also found to be the case in $C$. lagopus by Hanna (9). The number of sex classes of haplonts present in a species depends on the number of pairs of sex factors involved, and on the point in meiosis at which segregation occurs. From the results obtained in Coprinus ephemerus f. bisporus and Galera tenera $\mathrm{f}$. bispora, it is probable that more than one pair of factors are involved. It would no doubt be necessary to isolate several thousand monosporous mycelia to obtain enough viable haploid mycelia to yield more significant results. The magnitude of such a task places it beyond the scope of the present investigation.

\section{The Relation Between Nuclear Phenomena and Sex Reactions}

\section{(I) The Four-spored Forms}

The distribution of sex factors and the consequent sex reactions are explainable on the basis of observed nuclear phenomena. Scheme I (textfig. 3) illustrates the interpretation in heterothallic four-spored forms; in the bisexual ${ }^{6}$ type, segregation occurs during the first division, whereas in the quadrisexual type segregation takes place during the second division.

"The term "bisexual" as used here, does not imply that a given thallus carries the potentialities for two sexes. The term is used to signify that in a species or form the haplonts fall into two sex classes. "Quadrisexual" means that there are four sex classes of haploid mycelia. 
Coprinus ephemerus and possibly C. rostrupianus are examples of the bisexual type, the nuclear cycle of which is shown in scheme I. I have not studied agarics of the quadrisexual type.

A satisfactory factorial interpretation of homothallism in four-spored forms can only be formulated if we make certain assumptions. If only four nuclei are formed through the divisions of the fusion nucleus and each

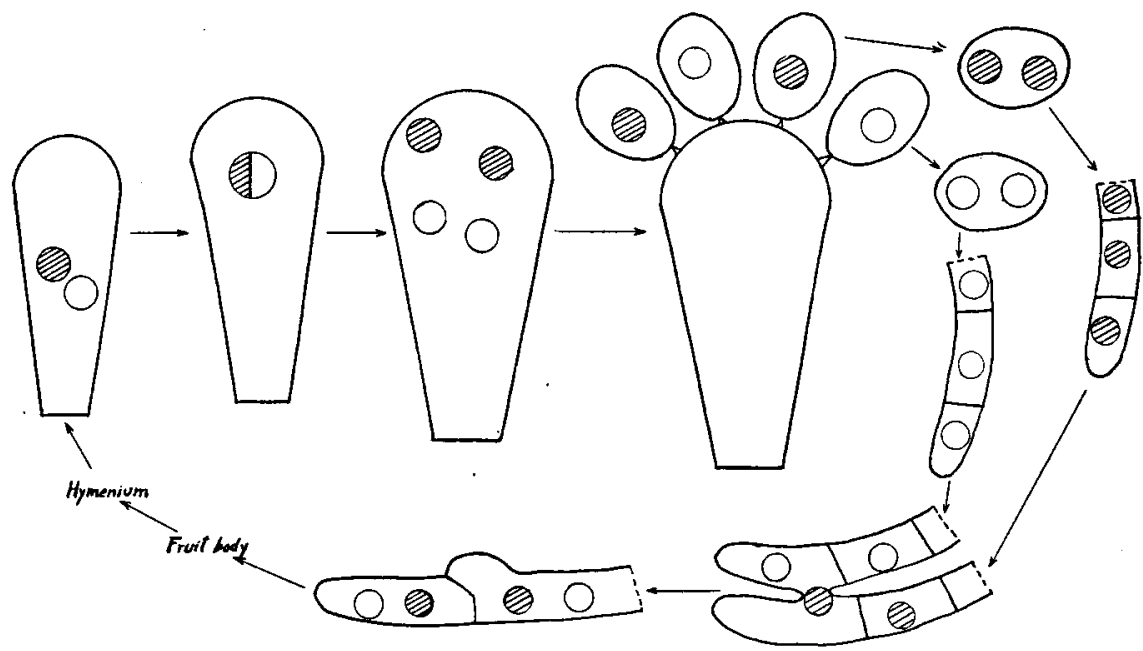

Text FIG. 3, (Scheme I). Bisexual heterothallism of four-spored forms. This scheme satisfies the cytological and cultural data on Coprinus ephemerus Fr., and may be general for bisexual forms.

of the four spores receives one nucleus, in order that each spore may receive the full set of sex factors, it is necessary to assume that no segregation of sex factors occurs. In this case the spore receives a diploid nucleus. In many agarics one nuclear division occurs in the spore. Since karyogamy occurs in the type of life cycle in question, it is necessary that meiosis, accompanied by segregation, occur at some point in the nuclear cycle. It is generally conceded that in Basidiomycetes segregation may occur in either division of meiosis. Dodge (6) entertains the plausibility of segregation occurring in the third nuclear division in the ascus. If we extend this hypothesis to the Basidiomycetes, we may assume that segregation occurs in the division of the spore nucleus. In that case the mycelium derived from the spore contains two kinds of haploid nuclei, differing in the sex factors which they carry. Scheme II (text fig. 4) satisfies the cytological conditions known in Coprinus sterquilinus, $C$. sclerotigenus, and perhaps other fourspored homothallic agarics. It is desirable to emphasize that the cytological data do not indicate whether chromosome reduction occurs in the basidium or in the spore. 


\section{(2) The Two-spored Forms}

Two-spored Hymenomycetes may be divided for present purposes into two categories on the basis of the nuclear cycle as follows: (I) Haploid forms, in which there is no karyogamy. The vegetative and hymenial cells are uniformly uninucleate and only one nuclear division occurs in the basidium. Each spore receives one nucleus and one nuclear division may occur in the spore; (2) Diploid forms, in which karyogamy occurs and is followed by meiosis, producing four nuclei in the basidium.

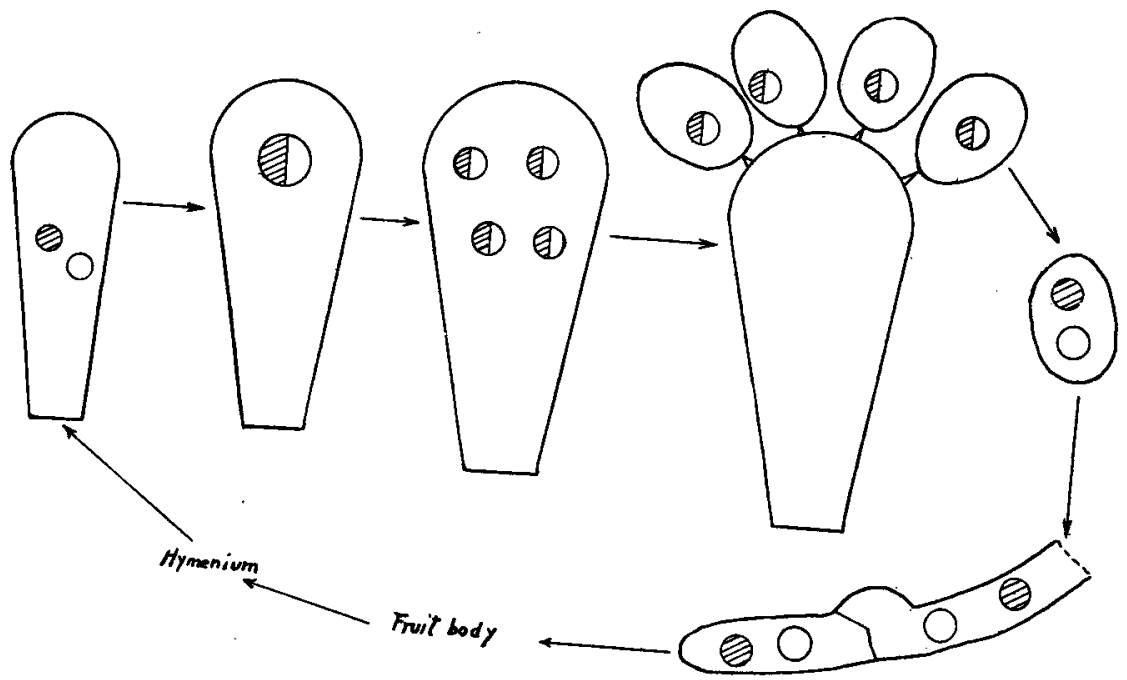

Text Fig. 4, (Scheme II). Homothallism in four-spored forms. The nuclear processes in Coprinus sterquilinus Fr. and C. sclerotigenus E. \& E., conform to this scheme. Cytological data do not indicate the place of segregation. This interpretation of homothallism on the basis of sex-bearing nuclei is hypothetical.

The haploid type is not particularly relevant to the present problem, because in the haploid nuclear cycle there is no karyogamy and consequently there are no manifestations of the usual phenomena of sexuality. A representative of this type, a two-spored form of Hygrophorus virgineus Fr., was studied by Bauch (I). I have collected a few fruit bodies of Hygrophorus borealis $\mathrm{Pk}$. var. subborealis Kauff., in which the basidia are two-spored. This plant is haploid, since there is no karyogamy and only one nuclear division occurs in the basidium. The field data are too limited to exclude the existence of a four-spored form, and if the four-spored form occurs we may have here a case similar to that reported by Bauch. I have made one collection consisting of three fruit bodies of Collybia cirrhata Fr. having twospored basidia. The four-spored form was very abundant in the same habitat. The two-spored form is haploid, but the condition in the four-spored form was not determined. The nuclei and basidia are too minute to be 
profitable material for more detailed study, but the respective nuclear cycles of the two forms probably agree with the situation found by Bauch in his Hygrophorus.

The two-spored forms of Coprinus ephemerus, Galera tenera, and Naucoria semiorbicularis obviously belong to the diploid type. Even in the absence of decisive chromosome counts, the cyclic recurrence of nuclear fusion followed by the formation of tetrads of nuclei in the basidia indicates that there is a diplophase and a haplophase. These two-spored forms are normally homothallic and it follows that the spore must carry a complete set of sex factors. I have shown that the spore usually receives two nuclei and it may be assumed that these two nuclei carry allelomorphic sex factors. The one or more nuclear divisions in the spore are probably vegetative.

The writer was unable to demonstrate the mechanism which governs the formation of spores and controls the distribution of nuclei to the spores. Hence we do not know whether two nuclei cooperate in the formation of a spore, nor do we know how two nuclei come to enter a spore. Dodge (6) has shown that in the ascomycete Neurospora tetrasperma Shear and Dodge, two non-sister nuclei may cooperate in delimiting an ascospore, thus forming a diploid, homothallic spore. Occasionally a single nucleus becomes incorporated in an ascospore, and it is this type of spore that is believed to give rise to an exceptional haploid mycelium.

In this Neurospora and in my two-spored agarics the final results of spore-formation are comparable because in both cases the formation of haploid and diploid spores on the same fruit body is proven and their occurrence is associated with certain observed nuclear phenomena. But the respective methods by which spores are delimited and the nuclei become incorporated in the spores are so fundamentally different in the Ascomycetes and Basidiomycetes that Dodge's cytological observations do not help us to understand the processes in these agarics. It may be suggested here that the occurrence of aberrant haplonts is due to an unstable condition of whatever mechanism is instrumental in distributing nuclei to the spores, so that occasionally a spore receives one nucleus. This nucleus may undergo one or more divisions in the spore, but all the resulting nuclei carry the same sex factor and the spore produces a haploid mycelium (scheme IV, text fig. 5). Investigators of sex phenomena in the rusts and smuts should be prepared to find comparable aberrations from the generalized nuclear cycle found in these pathogens.

Lewis (2r) has reported that in Amanita bisporigera Atk. each of the two spores receives one nucleus, and two nuclei remain behind in the basidium. I find no record of work on the sexuality of this species and have had no opportunity to study it. On the basis of Lewis' cytological data it is possible that Amanila bisporigera is heterothallic, as shown in scheme IV, but whether it is bisexual or quadrisexual remains to be determined by trial.

Since homothallism has been satisfactorily proven in species in which 
the spore is known to receive one nucleus, we must leave open the possibility that in a form in which the spore normally receives two nuclei, an exceptional spore may receive but one nucleus and nevertheless be homothallic. This assumption would presuppose that segregation had not occurred in the basidium.

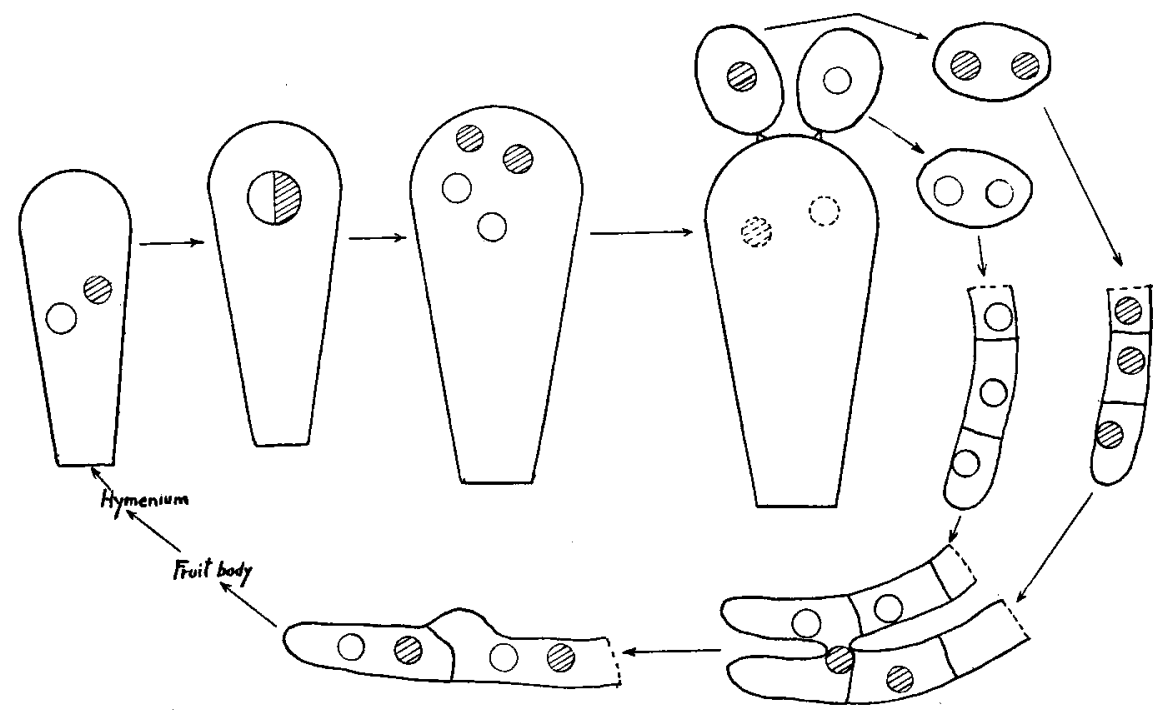

Text Fig. 5, (Scheme IV). Normal or aberrant heterothallism in two-spored forms. Aberrant sex reactions of Coprinus ephemerus f. bisporus and Galena tonera f. bispora are explainable on the basis of the known nuclear events shown in this scheme. Amanita bisporigera Atk. may also belong to this category.

We can expect that characteristics other than sex are determined by nuclear phenomena and perhaps by genetic factors. Many spores of Coprinus ephemerus f. bisporus fail to germinate, and the wide variations in the percentage of germination may have a cytological basis. Examination of the living hymenium shows that in a given area the spores are of the same size and there is no evidence of abortion of spores. It was found that the spores become nearly full-sized and sometimes begin to darken before nuclear migration begins. This may explain why spores that are picked from the basidia while still immature fail to germinate (Hanna, 9). Perhaps it is too radical to suggest that a spore may become full-grown and shed without having received a nucleus. It is possible that only certain of the tetracyte nuclei are capable of giving rise to a viable haploid spore. The formation of oidia in some of the haplonts of Galera tenera f. bispora may indicate a possible case of visible evidence of segregation, such as found by Dickinson (5).

The mycelium developed from the normal spore in these two-spored forms is homothallic, but the way in which the secondary condition arises is 
not the same in the three forms. In Galera tenera $\mathrm{f}$. bispora each cell of the mycelium, as early as the germ tube stage, is binucleate and clamp connections appear on the germ tube soon after it emerges from the vesicle. The secondary condition thus appears soon after germination, in fact there are no uninucleate haploid cells in the cycle. If we were to regard the number of nuclei in a cell as the criterion of the diploid or haploid condition, it would appear that in this agaric there is no haplophase. However, this criterion does not permit consiştent designation of various phases of the nuclear cycle, and it is desirable to regard the kind of nuclei rather than the number of nuclei as the deciding factor. Thus, the basidium with its single fusion nucleus is part of the diplophase, and a clamp-bearing hyphal cell with its two non-sister haploid nuclei is also part of the diplophase. Clamp connections are invariably associated with the synkaryons of binucleate diploid cells. The mature spore of a heterothallic four-spored form like Coprinus ephemerus contains two nuclei, but these are sister nuclei, and the spore should still be considered part of the haplophase. The coenocytic germ tube of a homothallic form, and also the multinucleate hyphal cells of Psalliota campestris (II, 28) belong to the diplophase. We may conclude that in Galera tenera f. bispora meiosis produces haploid nuclei, but there is no break in the association of synkaryons. The haploid condition is present only in the constitution of individual nuclei, but all cells of the plant are diploid.

The nuclear cycle is somewhat more complex in our two-spored Coprinus and Naucoria. In the former, the spore contains about eight nuclei, while in the latter the spore has four nuclei. Since the Coprini develop very rapidly, it seems possible that the large number of nuclei in the spore of this form is the result of precocious somatic divisions of the one or two nuclei which enter the spore. In both of the above forms the germ tube is coenocytic and the large and indefinite number of nuclei presumably belong, in the homothallic mycelium, to at least two sex classes.

In my preparations of germinated spores of the two-spored forms, I have been unable to identify the germ tubes of the aberrant haplonts, but the germ tube of a haploid spore may, in a cytological preparation, resemble the coenocytic tube of the normal homothallic spore, except that in the haploid germ tube the several nuclei would be of the same sex. Whether a coenocytic germ tube is heterothallic or homothallic probably depends on the kind of nuclei rather than the number of nuclei present.

The coenocytic germ tube in the case of Coprinus ephemerus $\mathrm{f}$. bisporus, and Naucoria semiorbicularis $\mathrm{f}$. bispora, soon develops into a uninucleate mycelium, the nuclei of which are assumed to fall into at least two sex classes, as shown in simplified form in scheme III (text fig. 6). Mlle. Bensaude (2) and Lehfeld (19) have figured conjugation between two uninucleate mycelia of opposite sex. Conjugation may occur soon after germination, practically between germ tubes (I9) or it may occur between cells 
of well-grown primary mycelia (2). In homothallic Mucors conjugation occurs between multinucleate hyphal cells (gametangia), the respective nuclei of which are believed to be of unlike sex. In view of these facts there is no reason for excluding the possibility that in our homothallic two-spored

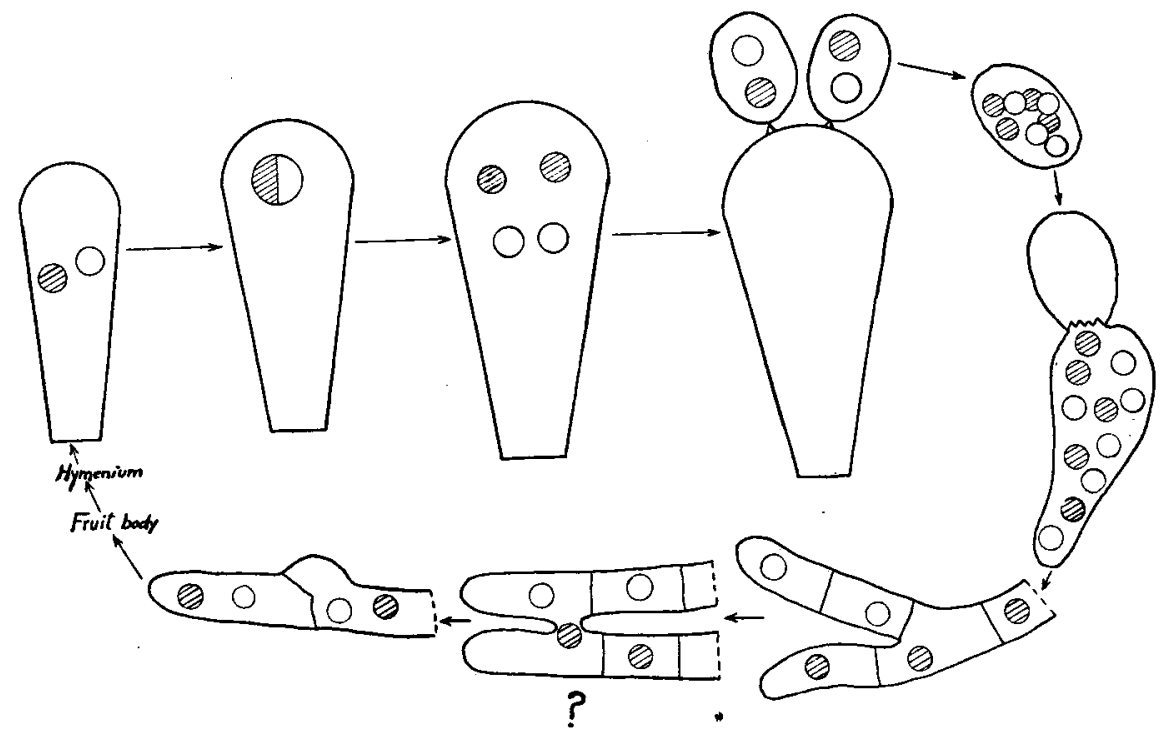

Text Fig. 6, (Scheme III). Homothallism in two-spored forms. The nuclear cycles of Coprinus ephemerus f. bisporus, Naucoria semiorbicularis f. bispora, and Galera tenera f. bispora follow this scheme. The stage marked (?) was not observed.

Coprinus and Naucoria conjugation occurs between two uninucleate but sexually unlike cells of a monosporous mycelium. If we can find a homothallic agaric in which the secondary condition arises very early, before its origin is obscured in a hyphal weft, we may expect to find the situation suggested in scheme III.

After the secondary condition is established, the nuclear cycle is the same in all three of our two-spored forms, and the cycle parallels, up to the time of spore formation, the nuclear cycle found in typical diploid forms having a clamp-bearing secondary mycelium.

The foregoing discussion is obviously opposed to the theory of heterohomothallism as advanced by Brunswik (3). According to Brunswik, a young monosporous mycelium of a homothallic species, during the time that it lacks clamp connections, is heterothallic. This condition sooner or later changes spontaneously to the clamp-bearing homothallic state. Hanna (9) has shown that the normal haplonts of Coprinus lagopus are sexually stable, and the present work indicates that aberrant haplonts also remain in the heterothallic condition. It is here suggested that a homothallic mycelium is homothallic as soon as it emerges from the spore, because 
the mycelium has received from the spore a complete set of sex factors. The clamp-bearing condition may appear early as in Galera tenera f. bispora. If the appearance of clamp connections is more or less delayed, their ultimate appearance is an expression of the change to strictly binucleate cells, either directly by septation, or by a progressive change to a uninucleate condition followed by conjugation between the resulting cells. A heterothallic mycelium is constantly haploid. A homothallic mycelium is, in some forms, constantly diploid, whereas in other homothallic forms, a monosporous mycelium is diploid in the sense that it carries nuclei of two sexes, but there is a brief period during which individual cells are haploid. Since this type of monosporous mycelium carries a full set of those factors which are necessary to bring about the clamp-bearing condition, the term "primary mycelium" is not appropriate. The designation "pseudo-primary mycelium" is here proposed.

Definite proof that mutation from the haploid to the diploid condition or vice versa may occur in the nuclear cycle of a Basidiomycete, would throw serious doubt on the value of the data on sex reactions in this group.

\section{SUMMARY}

In three species of agarics, i.e. Coprinus ephemerus Fr., Naucoria semiorbicularis Fr., and Galera tenera Fr. there is within the species a form with four-spored basidia and a form with two-spored basidia. The two forms of a species are essentially alike, except for the number of spores on their respective basidia, and a slight difference in spore size. Each form is constant for these characters.

The probable occurrence of similarly related four-spored and two-spored forms in many agarics is the basis for suggesting that rather than set up new species for the two-spored forms, the following trinomial designations be used; Coprinus ephemerus Fr., f. bisporus f. nov., Naucoria semiorbicularis Fr. f. bispora f. nov., Galera tenera Fr. f. bispora f. nov.

Limited data on haploid two-spored fruit bodies of Hygrophorus borealis Pk. var. subborealis Kauff. and of Collybia cirrhata Fr. indicate that there may be within a considerable number of species of agarics, four-spored diploid and two-spored haploid forms. This evidence supports the results obtained by Bauch.

The four-spored form of Coprinus ephemerus is heterothallic and bisexual. The results of matings are consistent with the hypothesis that sex is determined in this case by one pair of Mendelian factors. Cytological evidence indicates that the four-spored form of Galera tenera is probably heterothallic.

The two-spored form of each of the three species studied is normally homothallic.

In a large number of single-spore isolations of Coprinus ephemerus $\mathrm{f}$. bisporus, about to percent of the viable mycelia remained in the primary condition. In the case of Galera tenera $\mathrm{f}$. bispora about 4.5 percent of the 
viable monosporous mycelia remained primary. The haploid condition persists for at least two years, in both cases.

Mating experiments showed that the exceptional primary mycelia of both of the above forms react as haplonts, since certain pairings give rise to a characteristic secondary mycelium with clamp connections. The results suggest that if sex is determined by Mendelian factors, more than two pairs of independently segregating factors are involved.

In both the two-spored and the four-spored forms of the three species, there is an alternation of diplophase and haplophase, or their equivalents. Karyogamy occurs in the basidium and four nuclei are formed in the basidium by two nuclear divisions which probably represent meiosis.

In the nuclear cycle of Galera tenera f. bispora, all cells are normally diploid, the haploid condition being represented by the haploid nuclei of binucleate or multinucleate diploid cells. The clamp-bearing condition appears at the formation of the first septum of the germ tube, or very soon thereafter.

The germ tube of Coprinus ephemerus f. bisporus is coenocytic. This condition is soon succeeded by a uninucleate condition of short duration, followed by the binucleate clamp-bearing mycelium. It is suggested that conjugation occurs between uninucleate cells (of the same mycelium) containing sexually unlike nuclei.

Nuclear events in the mycelium of Naucoria semiorbicularis f. bispora approximate the condition found in Coprinus ephemerus f. bisporus.

In the four-spored forms, each spore receives one nucleus which divides once in the spore.

In the two-spored forms there was abundant evidence that a spore may receive two nuclei. In the case of Naucoria semiorbicularis $\mathrm{f}$. bispora and Galera tenera f. bispora, these two nuclei undergo one division. Several nuclear divisions occur in the spore of Coprinus ephemerus $\mathrm{f}$. bisporus before germination, and the mature spore contains approximately eight nuclei.

The two nuclei which enter the spore presumably are of opposite sex, giving rise to a homothallic spore.

Occasional spores were found to receive but one nucleus. A spore of this type is assumed to give rise to an aberrant haploid, uninucleate mycelium, and in order to produce a secondary mycelium, the haploid mycelium must be paired with another haploid mycelium, the nuclei of which carry allelomorphic sex factors. The occurrence of aberrant haploid mycelia is explainable on the basis of the observed nuclear phenomena. The sex reactions of such aberrant haplonts are not completely explained as yet on the basis of Mendelian sex factors.

The writer wishes to express his indebtedness to Professor C. H. Kauffman for his invaluable coöperation during the course of this work.

Department of Botany, UNIVERSity OF Michigan 


\section{LITERATURE CITED}

I. Bauch, R. Untersuchungen über zweisporige Hymenomyceten. I. Haploide Parthenogenesis bei Camarophyllus virgineus. Zeitschr. Bot. 18: 337-387. 1926.

2. Bensaude, Mathilde. Recherches sur le cycle évolutif et la sexualité chez les Basidiomycètes. (Thesis, Paris.) Nemours, 1918.

3. Brunswik, H. Untersuchungen über die Geschlechts- und Kernverhältnisse bei der Hymenomycetengattung Coprinus. Goebel's Bot. Abhandl. 5: I-I52. 1924.

4. Buller, A. H. R. Researches on Fungi, II. London, 1922.

5. Dickinson, S. Experiments on physiology and genetics of smut fungi. Proc. Roy. Soc. London. B, 103: 547-555. I928.

6. Dodge, B. O. Nuclear phenomena associated with heterothallism and homothallism in the ascomycete Neurospora. Jour. Agr. Res. 35: 289-305. 1927.

7. Gäuman-Dodge. Comparative morphology of fungi. New York, 1928.

8. Hanna, W. F. The problem of sex in Coprinus lagopus. Annals Bot. 39: 43I-457. 1925.

9. - - Sexual stability in monosporous mycelia of Coprinus lagopus. Annals Bot. 42: 379-389. 1928.

10. Harper, R. A. Binucleate cells in Hymenomycetes. Bot. Gaz. 33: I-24. 1902.

II. Hirmer, M. Zur kenntnis der Vielkernigkeit der Autobasidiomyzeten. Zeitschr. Bot. 12: $657-674$. 1920 .

12. Kniep, H. Beiträge zur Kenntnis der Hymenomyceten, I, II. Zeitschr. Bot. 5: 593-637. 19 ז 3 .

13. - Beiträge zur Kenntnis der Hymenomyceten, IV. Zeitschr. Bot. 8: 353-359. I9I6.

14. - - Beiträge zur Kenntnis der Hymenomyceten, V. Zeitschr. Bot. 9: 8I-I I8. 1917.

15. - - Über morphologische und physiologische Geschlechtsdifferenzierung. Verhandl. Physik.-Med. Ges. Würzburg 46: I-18. 1919.

16. - - Über Geschlechtsbestimmung und Reduktionsteilung. Verhandl. Physik.Med. Ges. Würzburg 47: 1-29. 1922.

17. Kühner, R. Etude cytologique de l'hymenium de Mycena galericulata. Le Botaniste I8: $169-176 . \quad 1927$.

I8. Lange, J. E. Studies in the agarics of Denmark. Dansk. Bot. Arkiv. 2: No. 3, Part II. 1915 .

19. Lehfeldt, W. Über die Entstehung des Paarkernmyzels bei heterothallischen Basidiomyzeten. Hedwigia 64:30-51. I923.

20. Levine, M. Studies in the cytology of the Hymenomycetes, especially the Boleti. Bull. Torrey Bot. Club 40: 137-18r. I9I3.

21. Lewis, C. E. The basidium of Amanita bisporigera. Bot. Gaz. 4I: 348-352. 1906.

22. Maire, R. Recherches cytologiques et taxonomique sur les Basidiomycètes. Paris, 1902.

23. Mounce, Irene. Homothallism and the production of fruit bodies by monosporous mycelia in the genus Coprinus. Trans. Brit. Mycol. Soc. 7: 198-217. r921.

24. -- Homothallism and heterothallism in the genus Coprinus. Trans. Brit. Mycol. Soc. 8: 256-269. 1922.

25. Newton, D. E. Bisexuality of individual strains of Coprinus Rostrupianus. Annals Bot. 40: 105-128. 1926.

26. Nichols, Susan P. Binucleate cells in basidiomycetes. Trans. Wisconsin Acad. Sci. 15: 35-70. I904.

27. Sass, J. E. Aberrant heterothallism in a homothallic Coprinus. Science 68: 5481928.

28. - A cytological study of a bi-spored form of Psalliota campestris. Papers Michigan Acad. Sci. 9, 1929. 
29. Stakman, E. C., and J. J. Christensen. Heterothallism in Ustilago Zeae. Phytopathol. I7: 827-834. I927.

30. Vandendries, R. Contribution nouvelles à l'étude de la sexualité des Basidiomycètes. La Cellule 35: 129-157. 1924.

\section{EXPLANATION OF PLATES}

The drawings were made with the aid of a camera lucida, using a Zeiss 2-mm. apochromatic objective, N.A. 1.4, and a series of compensating oculars. The magnification varies in keeping with the degree of detail to be shown in the various drawings.

\section{Plate LXIV}

FIGS. I-28, Coprinus ephemerus $\mathrm{f}$. bisporus, $\times 2200$.

Frg. I. Young binucleate basidium, prior to karyogamy.

Fig. 2. Fusion nucleus in the basidium. Note the method of insertion of basidium on a subhymenial cell.

FIGs. 3-8. Pre-meiotic changes in the fusion nucleus, with the formation of the chromosome group. The limits of the fusion nucleus are scarcely perceptible in figure 7 .

FIGS. 9-13. First division of the fusion nucleus.

FIGS. I4-16. Interkinesis.

FIG. I7. Spindles of conjugate second division. The spindles are not parallel. parallel.

FIG. I8. Telophase of second division. The spindles in this case were probably

FIG. I9. Four nuclei resulting from meiosis.

FIGS. 20-23. Formation of sterigmata and spores. Note the varied arrangement of the tetracyte nuclei in the basidium. (Figs. $2 \mathrm{I}-23$ on Pl. LXV.)

FIG. 24. Migration into a spore, of a chromatin filament derived from a nucleus. A second nucleus appears to be in a stage preparatory to migration. nucleus.

FIG. 25. The migration of a second nucleus into a spore which already contains one

\section{Plate LXV}

FIGS. 26-28. Three immature spores containing respectively 1,2 , and 3 nuclei. In figure 28 a nucleus appears to be in a stage of division.

\section{FIGS. 29-5I, Coprinus ephemerus $\mathrm{f}$. bisporus, $\times 1000$.}

FIg. 29. A mature spore containing at least eight nuclei, from a microtome section.

FIgs. 30-3I. The vesicle emerging through the germ pore. Four nuclei are evident in figure $3 \mathrm{I}$.

FIGs. 32-34. Non-septate, multinucleate germ tubes. Figure 32 was drawn from a heavily overstained preparation.

FIGs. 35-36. Septate, multinucleate germ tubes. Flemming fixation, iron haematoxylin stain.

FIGs. 37-44. The septate "pseudo-primary" mycelium, the cells of which contain from one to many nuclei.

FIGS. 45-47. The primary mycelium having uninucleate cells, derived from the "pseudo-primary" mycelium by septation. (Fig. 47 on PI. LXVI.)

\section{Plate LXVI}

FIGs. 48-49. Hyphae of the secondary mycelium, showing stages of the formation of clamp connection.

FIG. 50. Intermingled pseudo-primary and secondary hyphae, from a preparation made when the secondary hyphae were just appearing on the margin of the mycelium.

FIG. 5I. Hyphae of an aberrant haploid mycelium. 


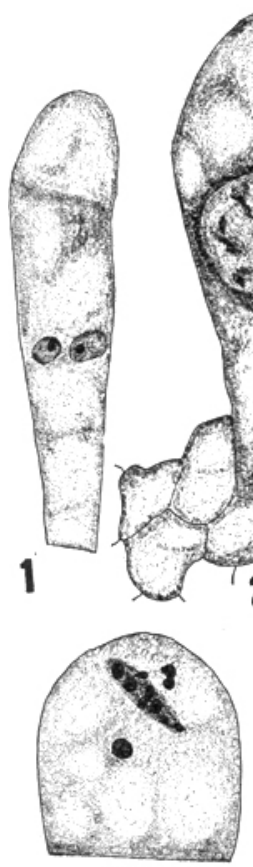

9

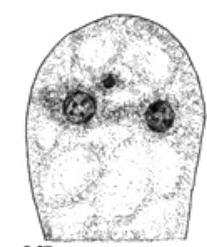

14

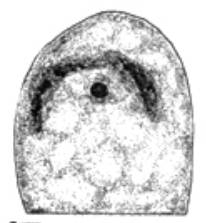

17

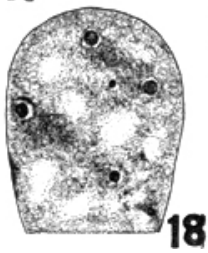

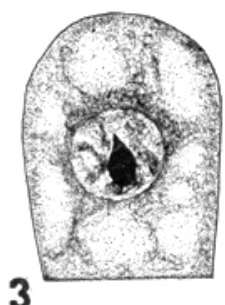
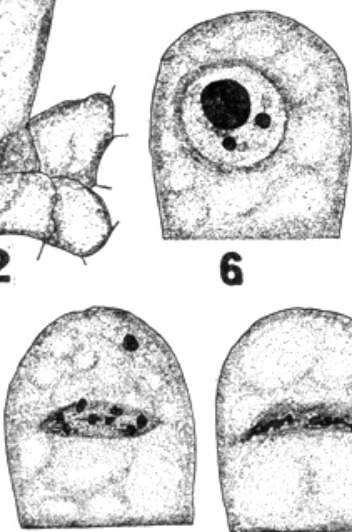

10

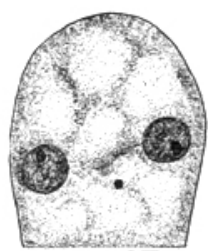

15

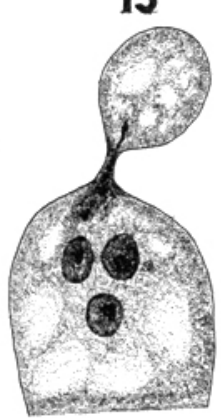

24
6

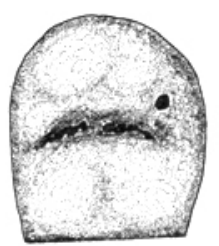

11

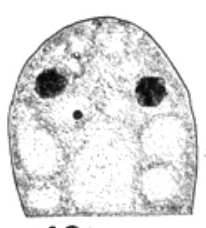

16
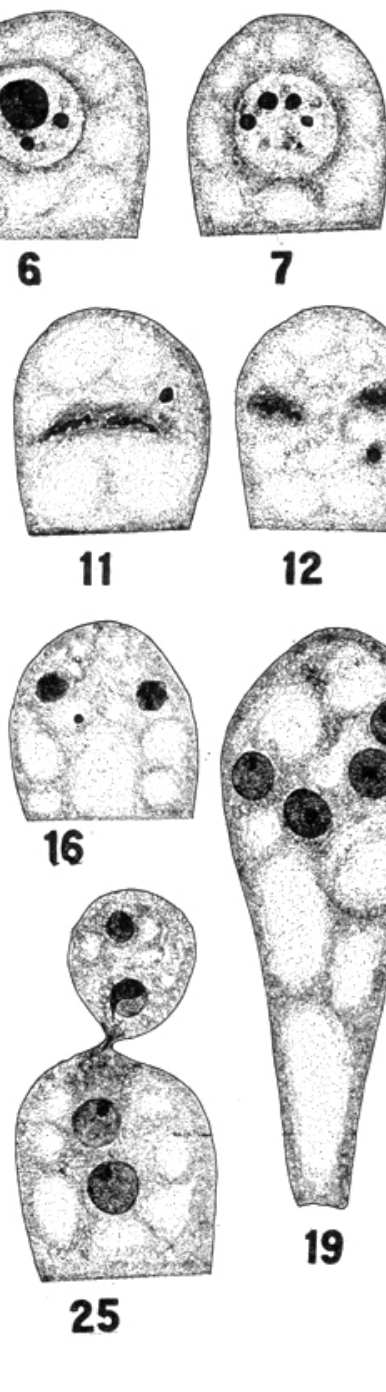

7

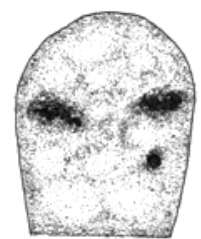

12

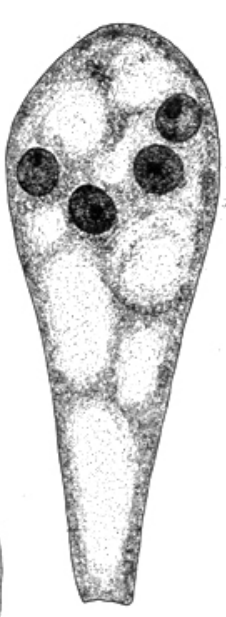

19

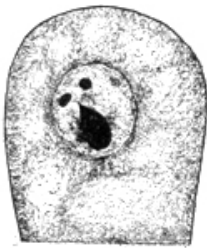

5

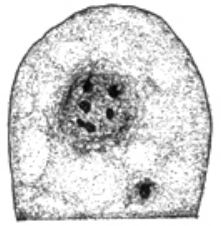

8

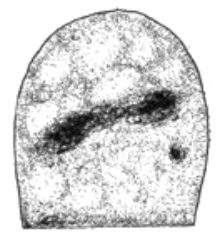

13

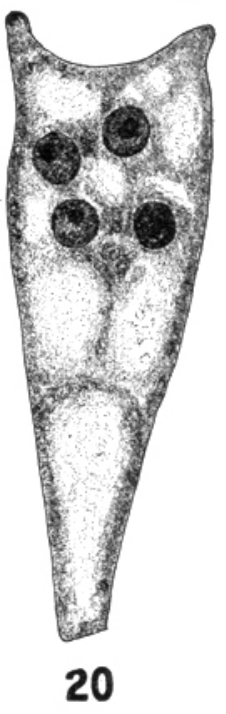

Sass: Agaricaceae 
AMERICAN JOURNAL OF Botany.
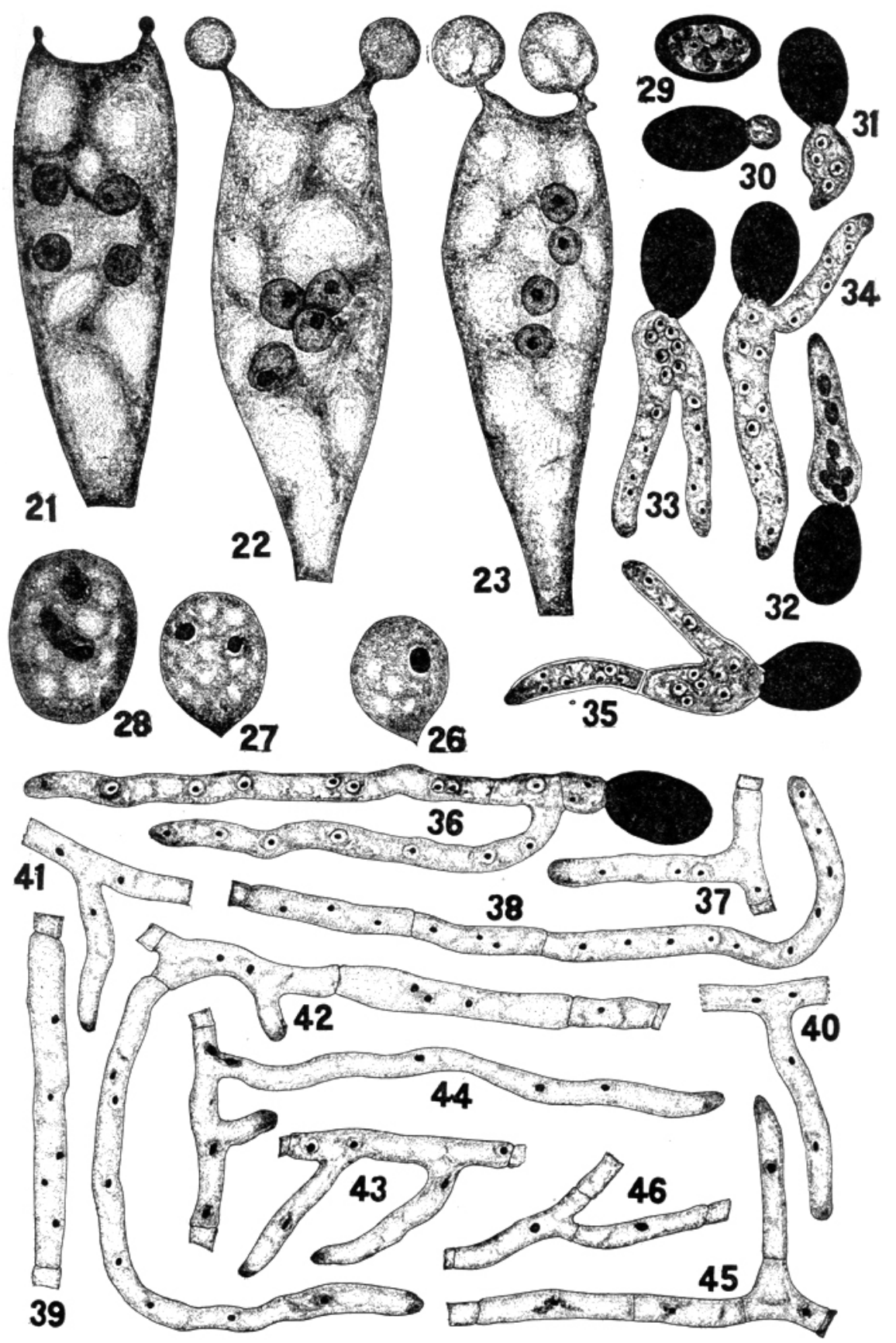

Sass: Agaricaceae

Volume XVI, Plate LXV. 


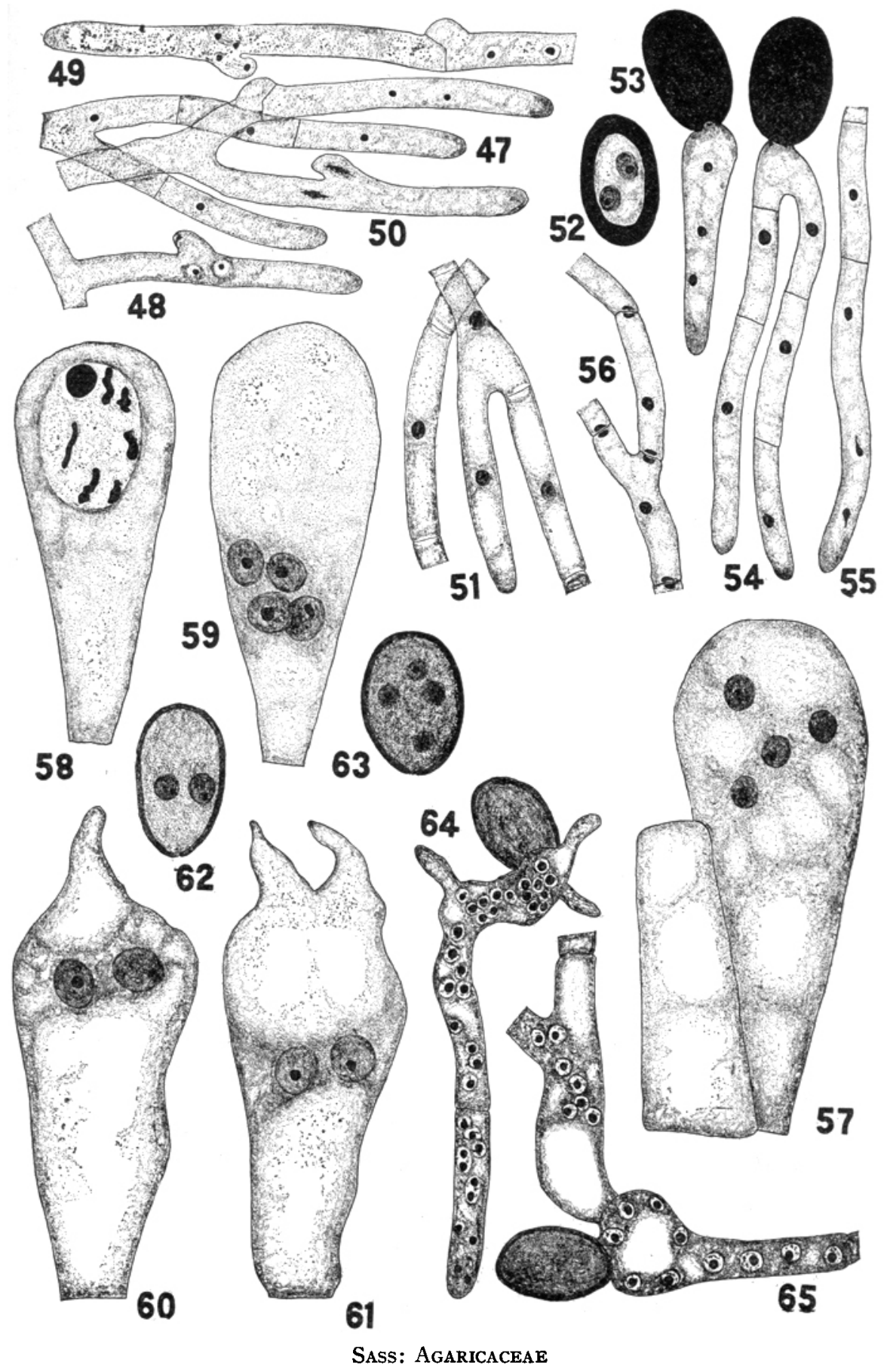




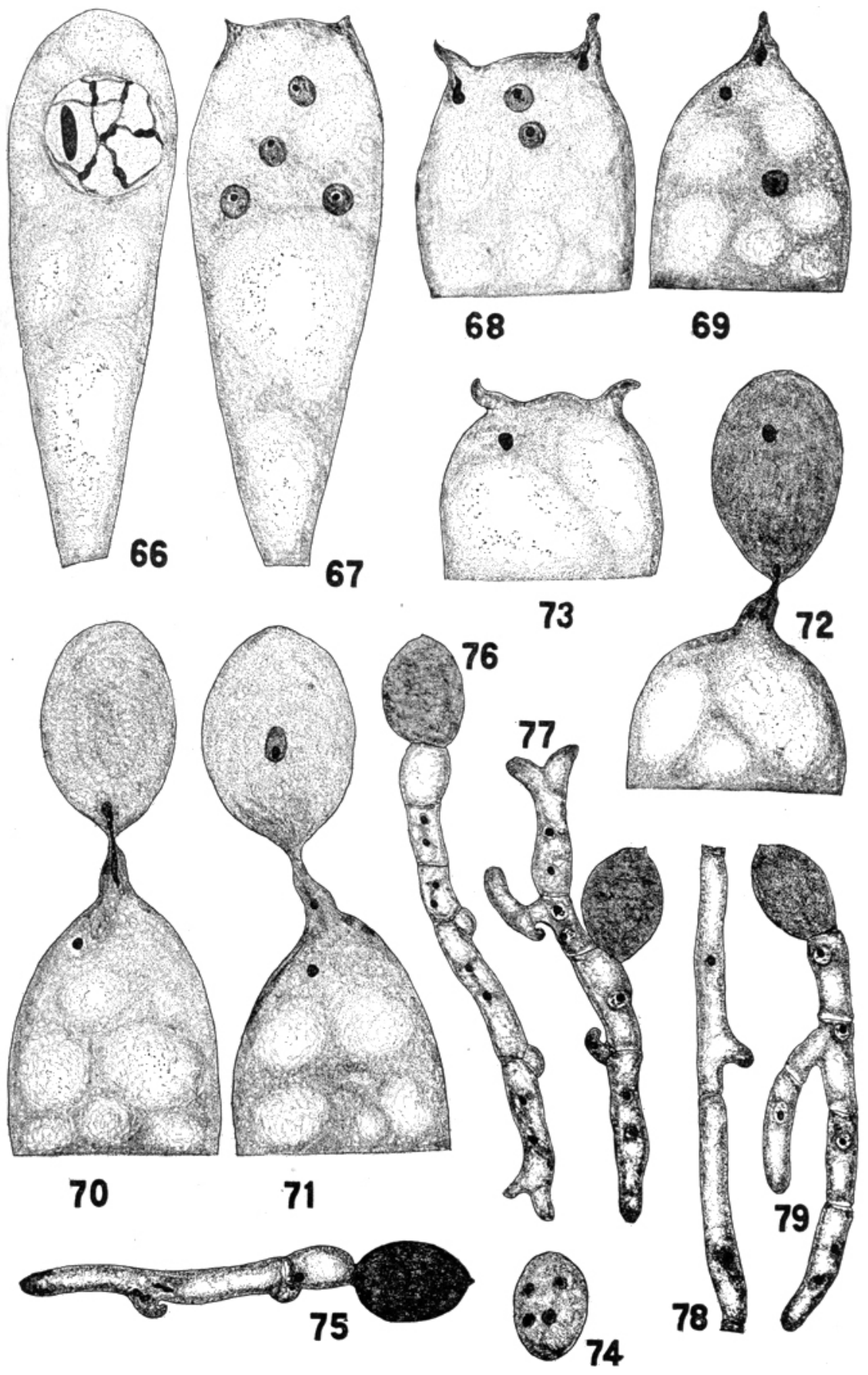

SASS: AgaricaceaE 
FIGS. 52-57. Coprinus ephemerus, (four-spored). FIGS. 52-56, $X$ Iooo; FIG. 57, $\times 2200$.

FIG. 52. Mature binucleate spore, from a microtome section. Occasional spores containing three nuclei occur.

FIG. 53. Non-septate germ tube containing three nuclei.

FIGs. 54-56. Mycelium of various ages, having uninucleate cells. The terminal cells frequently appear to contain more than one nucleus.

FIG. 57. Basidium containing the tetracyte nuclei.

FIGs. 58-63, Naucoria semiorbicularis $\mathrm{f}$. bispora, $\times 2000$.

FIG. 58. Large fusion nucleus shortly before the first division.

FIG. 59. Tetracyte nuclei resulting from meiosis.

FIGS. 60-6r. Collapsed basidia containing two residual nuclei.

FIG. 62. Immature spore containing two nuclei.

FIG. 63. Nearly mature spore containing four nuclei.

FIGS. 64-65. Naucoria semiorbicularis $\mathrm{f}$. bispora, $\times$ I Ioo, showing large well-defined nuclei in germ tubes. In the intercalary cells of older mycelium the nuclei are larger in proportion to the diameter of the hypha.

\section{Plate LXVII}

FIGS. 66-73. Galera tenera f. bispora, $\times 2500$.

FIG. 66. Fusion nucleus with lenticular nucleolus and a well-defined reticulum.

FIG. 67. Tetracyte nuclei in a basidium on which two sterigmata are just forming.

FIG. 68. A nucleus preparing for migration, one under - ach sterigma.

FIG. 69. A nucleus in the base of a sterigma; a second nucleus nearby lacks the nuclear membrane and is apparently preparing to migrate.

FIG. 70. A chromatin filament entering a spore.

FIGS. $7 \mathrm{I}-72$. A second nucleus entering a spore which already contains one nucleus.

Frg. 73. Collapsed basidium containing one residual nucleus.

FIGs. 74-78. Galera tenera f. bispora, $X$ I200.

FIG. 74. Immature spore containing four nuclei.

FIGS. 75-77. Development of the germ tube, showing early appearance of clamp connections.

FIG. 78. Uninucleate cells of an aberrant haploid mycelium.

FIG. 79. Galera tenera (four-spored), $X$ I200. Uninucleate cells of a normally primary monosporous mycelium. 